Article

\title{
Synthetic Strategy and Anti-Tumor Activities of Macrocyclic Scaffolds Based on 4-Hydroxyproline
}

\author{
Guorui Cao ${ }^{1}$, Kun Yang ${ }^{1}$, Yue $\mathrm{Li}^{1}$, Longjiang Huang ${ }^{1,2}$ and Dawei Teng ${ }^{1, *}$ \\ 1 College of Chemical Engineering, Qingdao University of Science and Technology, Qingdao 266042, China; \\ llxx.love@163.com (G.C.); yk060606@126.com (K.Y.); a4931778@163.com (Y.L.); routechem@163.com (L.H.) \\ 2 State Key Laboratory of Bioactive Substance and Function of Natural Medicines, Institute of Materia Medica, \\ Chinese Academy of Medical Sciences and Peking Union Medical College, Beijing 100050, China \\ * Correspondence: dteng@qust.edu.cn; Tel./Fax: +86-532-6807-4518
}

Academic Editor: Derek J. McPhee

Received: 10 January 2016 ; Accepted: 4 February 2016 ; Published: 15 February 2016

\begin{abstract}
A series of novel 13- to 15-member hydroxyproline-based macrocycles, which contain alkyl-alkyl ether and alkyl-aryl ether moieties, have been synthesized by the strategy of macrocyclization utilising azide-alkyne cycloaddition, Mitsunobu protocol and amide formation. Their anti-tumor activities towards A549, MDA-MB-231 and Hep G2 cells were screened in vitro by an MTT assay. The results indicated that 13-member macrocycle 33 containing alkene chain showed the best results, exhibiting the highest inhibitory effects towards lung cancer cell line A549, which was higher than that of the reference cisplatin $\left(\mathrm{IC}_{50}\right.$ value $\left.=2.55 \mu \mathrm{mol} / \mathrm{L}\right)$.
\end{abstract}

Keywords: macrocycle; 4-hydroxyproline; azide-alkyne cycloaddition; Mitsunobu reaction; amide formation; anti-tumor activity

\section{Introduction}

Macrocycles are commonly found in bioactive natural products and used as valuable source of bioactive molecules in drug discovery. They can demonstrate drug-like physicochemical and pharmacokinetic properties such as good solubility, lipophilicity, metabolite stability and bioavailability [1,2]. Macrocyclic structures could provide a compromise between structural pre-organization and sufficient flexibility to mould to a target protein surface and maximize binding interactions [3]. They also have a favorable impact on other essential properties required for drugs, such as membrane permeability, metabolic stability, increased potencies, better receptor selectivity and overall pharmacokinetics [4-7]. The aryl ether moiety is a common structural motif of many bioactive macrocyclic natural products such as vancomycin family of antibiotics [8-11], noncompetitive ACE inhibitor K-13 [12,13], piperazinomycin [14-16], and serine-based macrocycles representing $\beta$-turn mimetics [17-20]. Some hydroxyproline-based macrocycles have been introduced into important drugs, such as ACE inhibitor zizyphine [21-23], alkaloid paliurine E [24], and the echinocandin family including anidulafungin, caspofungin, and micafungin [25-28]. Recently, HCV NS3 protease inhibitors vaniprevir (MK-7009) [29,30], ITMN-191 [31], and BILN 2601 [32] were advanced into clinical development.

Inspired by the numerous aryl-ether moieties found in nature and hydroxyproline-based macrocycles discovered in drugs (Figure 1), we designed macrocyclic structures that incorporated aryl-ether and hydroxyproline fragments. Furthermore, another two fragments were introduced into the target structures to provide macrocycles of suitable size and conformation (Figure 2). It is well known that macrocycle size is carried out prior to the synthesis of macrocycles-large enough not to be strained and small enough to avoid clashes with the protein. As part of our previous 
efforts on exploring biologically important heterocyclic compounds and natural products [33-35], we herein report the successful synthesis of a collection of 13- to 15-member macrocyclic scaffolds, which incorporate 1,3-benzene rings and hydroxyproline, and evaluate their anti-tumor activities toward human tumor cell lines A549, MDA-MB-231 and Hep G2.
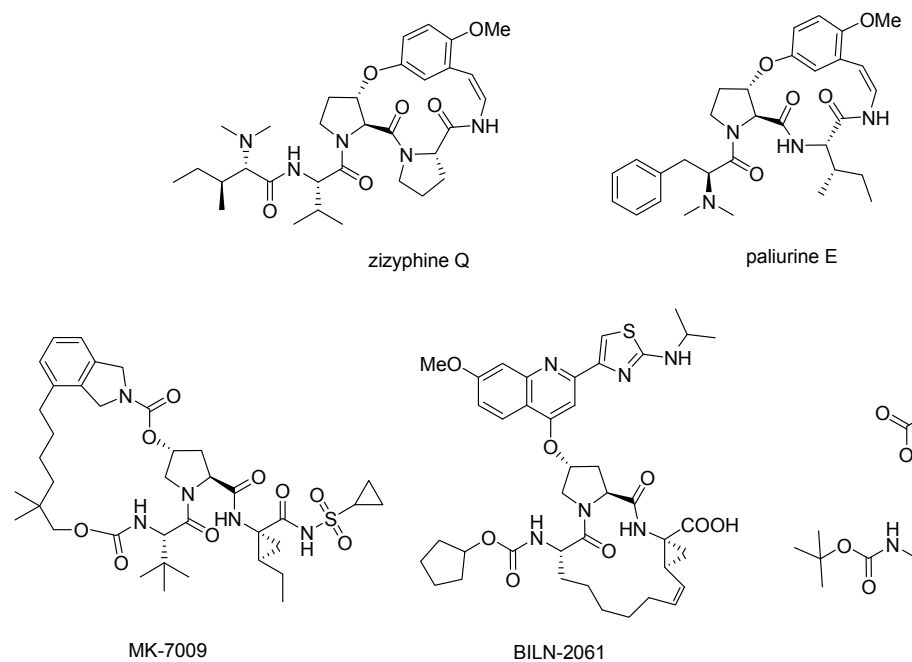

BILN-2061

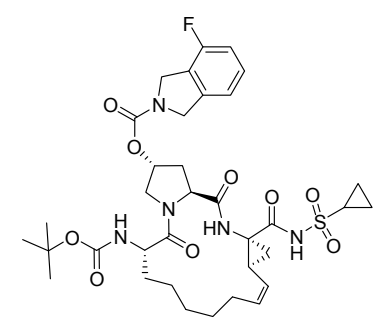

ITMN-191

Figure 1. Hydroxyproline-containing nature products and drugs.
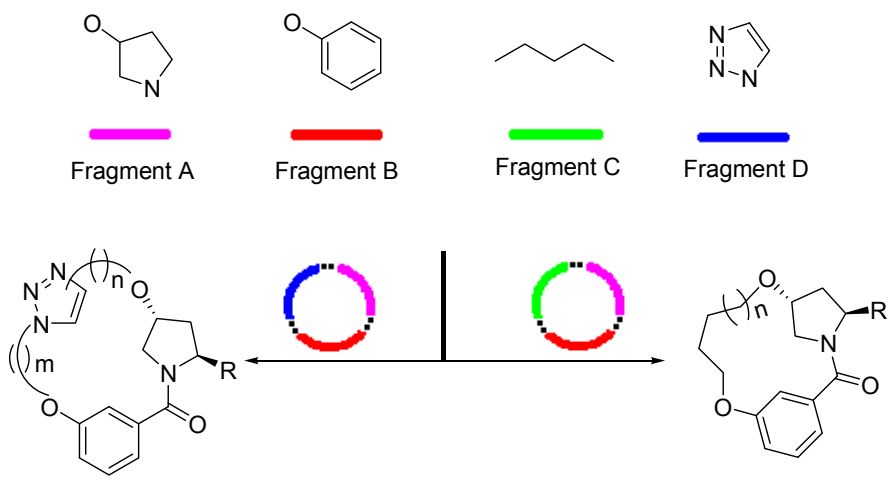

Figure 2. Target macrocyclic structures.

\section{Results and Discussion}

\subsection{Chemistry}

Of all the macrocyclization methods, Huisgen 1,3-dipolar cycloaddition [36] of azides and alkynes is proposed to construct a triazole-linker to cyclize the macrocyclic ring. Apparently, it is straightforward and the ring size could be easily manipulated. Under thermal conditions, the reactions produce a mixture of 1,4- and 1,5-disubstituted 1,2,3-triazole regioisomers. This was overcome by the discovery of $\mathrm{Cu}(\mathrm{I})$-catalyzed azide-alkyne cycloaddition (CuAAC) [37-42] and ruthenium-catalyzed azide-alkyne cycloaddition (RuAAC) [43-45], which could lead regioselectively to 1,4-disubstituted and 1,5-disubstituted 1,2,3-triazoles. The synthesis was illustrated in Scheme 1. trans-4-Hydroxy-L-proline (1) was sequentially esterified, $N$-protected with a Boc group, alkylated with 3-bromopropyne, and $\mathrm{N}$-deprotected under acidic conditions to afford alkyne 2. 3-Hydroxybenzoic acid (3) was sequentially methylated with thionyl chloride in methanol, alkylated with 1-bromo-2-chloroethane, substituted by sodium azide, and hydrolysed to afford azide 4 . Reaction of alkyne 2 with azide 4 affords 5 under amide formation conditions (Scheme 1). 


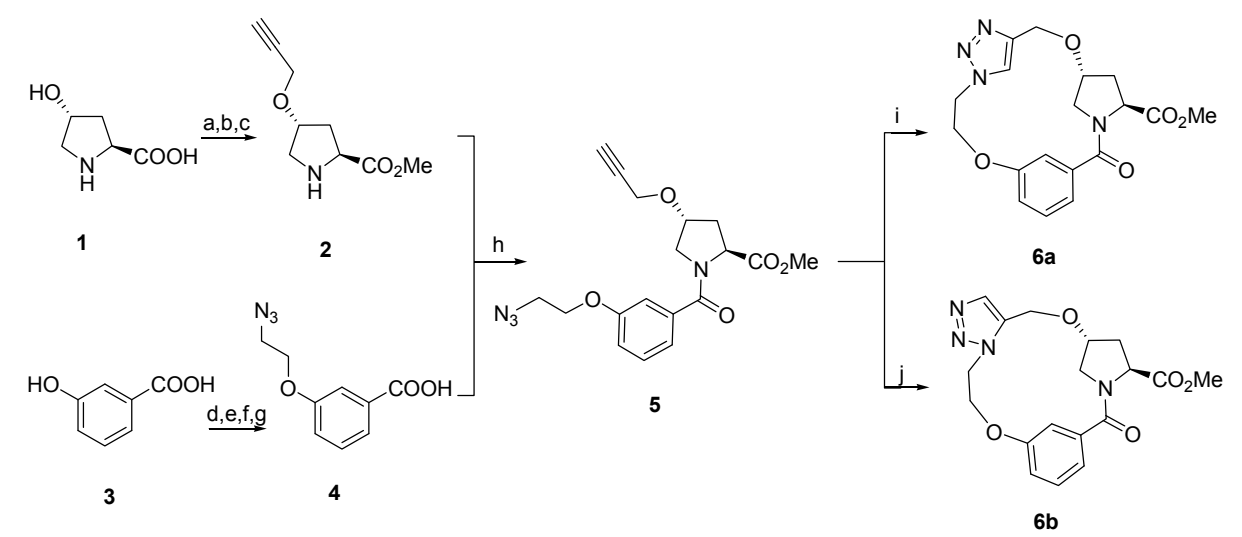

Scheme 1. Macrocyclization with azide-alkyne cycloaddition. Reagents and conditions: (a) (i) $\mathrm{SOCl}_{2}$, $\mathrm{MeOH}$, reflux, $5 \mathrm{~h}$; (ii) (Boc) ${ }_{2} \mathrm{O}, \mathrm{MeOH}, 0{ }^{\circ} \mathrm{C}-$ r.t., 2 h, 85\%; (b) 3-Bromo-propyne, NaH, DMF, $0{ }^{\circ} \mathrm{C}$-r.t., overnight, 37\%; (c) 3M HCl/EtOAc, r.t., 2 h, 95\%; (d) $\mathrm{SOCl}_{2}, \mathrm{MeOH}$, reflux, 5 h, 96\%; (e) 1-Bromo-2-chloro-ethane, $\mathrm{NaH}, \mathrm{DMF}, 0{ }^{\circ} \mathrm{C}$-r.t., overnight, $34 \%$; (f) $\mathrm{NaN}_{3}, \mathrm{DMF}, 50{ }^{\circ} \mathrm{C}, 2 \mathrm{~h}, 85 \%$; (g) $\mathrm{NaOH}, \mathrm{MeOH} / \mathrm{H}_{2} \mathrm{O}, 3 \mathrm{~h}, 92 \%$; (h) $\mathrm{HOBt}, \mathrm{EDCI}, \mathrm{Et}_{3} \mathrm{~N}, \mathrm{CH}_{2} \mathrm{Cl}_{2}, 90 \%$; (i) CuI, toluene, reflux, $2 \mathrm{~h}$, $43 \%$; (j) $\left[\mathrm{Cp}^{*} \mathrm{RuCl}\right]_{4}$, toluene, $80{ }^{\circ} \mathrm{C}, 4 \mathrm{~h}, 42 \%$.

With compound 5 in hand, the intramolecular 1,3-dipolar cycloaddition was conducted under various conditions (Table 1). Under thermal conditions, a mixture of 1,4- and 1,5-disubstituted triazole linkers was obtained in a ratio of 5:1 after refluxing in toluene (Entry 1). Under CuAAC conditions, the reaction led exclusively to the 1,4-disubstituted triazole linker 6a in 55\% yield (Entry 2). Under RuAAC conditions, the cyclization failed employing $\mathrm{Cp} * \mathrm{RuCl}(\mathrm{COD})$ as catalyst, possibly due to the thermal instability of the catalyst [46] (Entries 3, 4). After several attempts, we found that the macrocycle with 1,5-disubstituted triazole linker was formed using $\mathrm{Cp} * \mathrm{RuCl}\left(\mathrm{PPh}_{3}\right)_{2}$ as catalyst (Entry 5). However, the product was hard to isolate from the phosphine oxide formed in the reaction [47]. Improved result was achieved with $\left[\mathrm{Cp}^{*} \mathrm{RuCl}_{4}\right.$ as catalyst in toluene at $80{ }^{\circ} \mathrm{C}$ in $48 \%$ yield (Entry 6). Compared to 15 -membered macrocycle $6 \mathbf{a}, 14$-membered product $\mathbf{6 b}$ was obtained in lower yield and the reaction needed longer time (Entries 2 and 7).

Table 1. Macrocyclization with azide-alkyne cycloadditon ${ }^{\mathrm{a}}$.

\begin{tabular}{ccccccc}
\hline Entry & Catalyst & Temperature $\left({ }^{\circ} \mathbf{C}\right)$ & Time (h) & Ring Size & Yield (\%) & Ratio (1,4-:1,5-) \\
\hline 1 & Thermal & 110 & 24 & 15,14 & 20 & $5: 1$ \\
2 & $\mathrm{CuI}$ & 110 & 2 & 15 & 55 & $>99: 1$ \\
3 & $\left.\mathrm{Cp} \mathrm{puCl}^{*} \mathrm{RoD}\right)$ & 50 & 24 & 14 & 0 & - \\
4 & $\mathrm{Cp} R \mathrm{RuCl}(\mathrm{COD})$ & 110 & 24 & 14 & 0 & - \\
5 & $\mathrm{Cp} \mathrm{RuCl}^{2}(\mathrm{PPh})_{3}$ & 80 & 8 & 14 & 33 & $<1: 99$ \\
6 & {$\left[\mathrm{Cp} \mathrm{RuCl}_{4}\right.$} & 80 & 4 & 14 & 48 & $<1: 99$ \\
7 & {$\left[\mathrm{Cp} \mathrm{RuCl}_{4}\right.$} & 110 & 4 & 14 & 41 & $<1: 99$ \\
\hline
\end{tabular}

${ }^{a}$ Reaction conditions: $0.3 \mathrm{mmol}$ scale, $5 \mathrm{~mol} \%$ of catalyst, toluene, $0.02 \mathrm{M}^{\mathrm{b}}$ Isolated yield.

Encouraged by the results of macrocyclizations with azide-alkyne cycloadditions, we continued our investigation by performing the transformation of trans-4-hydroxy-L-proline (1) to 10a. Retro-synthetic analysis indicates that 13-member macrocycle 10a could be cyclized in four ways by ring-closing metathesis (RCM) [48-52]/hydrogenation reaction (path $a$ ), intramolecular Mitsunobu reaction (path $b, c$ ) and by amide formation reaction (path $d$ ). As shown in Scheme 2 . trans-4-Hydroxy-L-proline (1) was sequentially esterified, N-protected with Boc group, alkylated with 3-bromopropene, $\mathrm{N}$-deprotected and condensed under amide formation conditions to afford dialkene $\mathbf{8}$. However, the cyclization of $\mathbf{8}$ failed under various conditions with both first and second generation Grubbs' catalyst (path $a$ ). The results indicated that the conformation of 8 was not favored 
for the macrocyclization under RCM conditions. This is presumably caused by the rigid meta benzene junction that results in lower probability of encounter and increasing greater strain in the ansa-bridged macrocycles, which greatly reduces the effective morality (EM) of the terminal dienes [53-55].

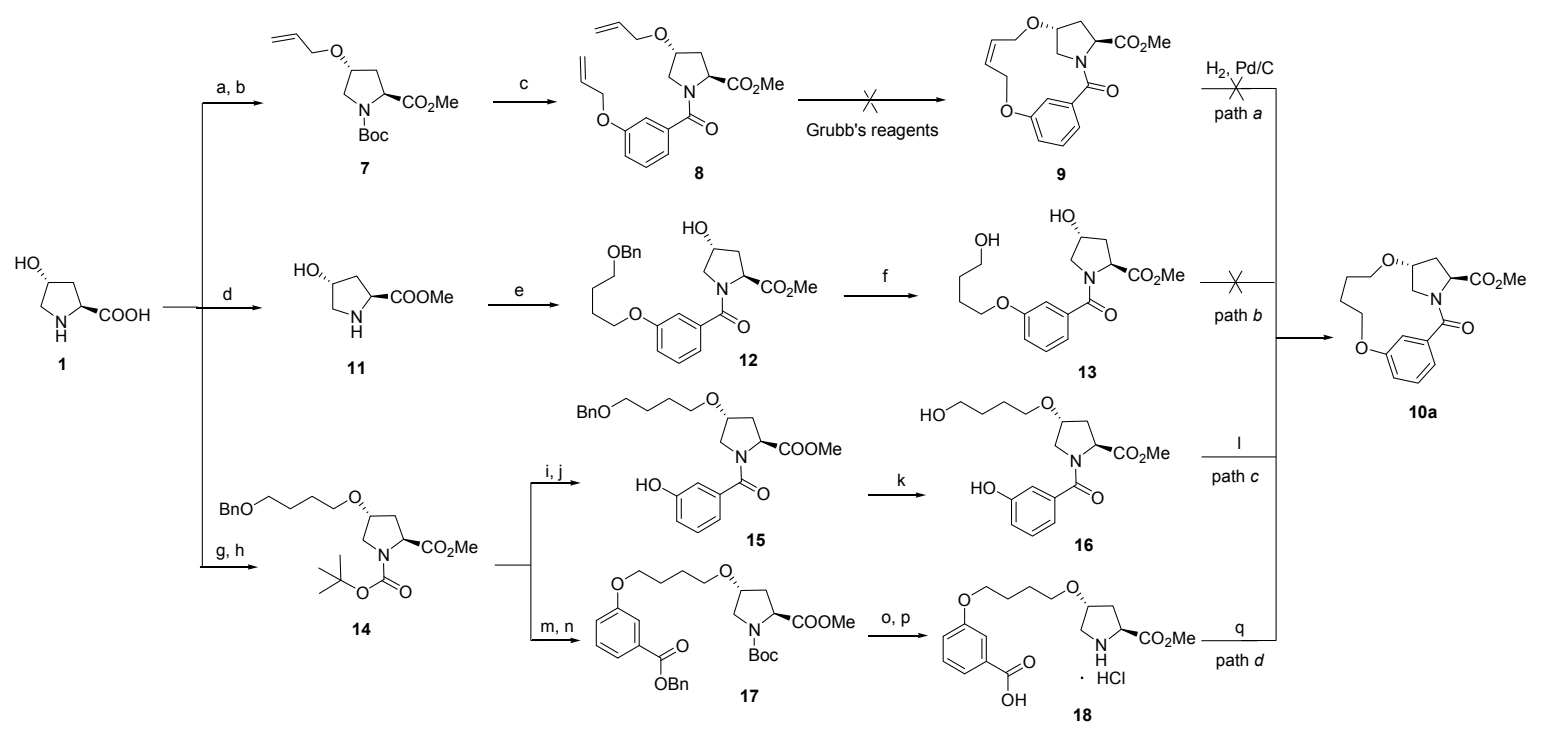

Scheme 2. Macrocyclization of 10a in four ways. Reagents and conditions: (a) (i) $\mathrm{SOCl}_{2}, \mathrm{MeOH}$, reflux, overnight; (ii) (Boc) ${ }_{2} \mathrm{O}, \mathrm{Et}_{3} \mathrm{~N}, \mathrm{MeOH}, 0{ }^{\circ} \mathrm{C}$-r.t., $2 \mathrm{~h}, 96 \%$; (b) 3-bromoprop-1-ene, $\mathrm{NaH}, \mathrm{DMF}, 0{ }^{\circ} \mathrm{C}-$ r.t., $4 \mathrm{~h}, 35 \%$; (c) (i) $3 \mathrm{M} \mathrm{HCl} / \mathrm{EtOAc}$, r.t., $2 \mathrm{~h}$; (ii) 3-(allyloxy)benzoic acid, $\mathrm{HOBt}, \mathrm{EDCI}, \mathrm{Et}_{3} \mathrm{~N}, \mathrm{CH}_{2} \mathrm{Cl}_{2}$, $0{ }^{\circ} \mathrm{C}$-r.t., $2 \mathrm{~h}, 71 \%$; (d) $\mathrm{SOCl}_{2}, \mathrm{MeOH}$, reflux, overnight, 96\%; (e) 3-(4-(benzyloxy)butoxy)benzoic acid, $\mathrm{HOBt}, \mathrm{EDCI}, \mathrm{Et}_{3} \mathrm{~N}, \mathrm{CH}_{2} \mathrm{Cl}_{2}, 0{ }^{\circ} \mathrm{C}$-r.t., $2 \mathrm{~h}, 75 \%$; (f) $\mathrm{H}_{2}, \mathrm{Pd} / \mathrm{C}, \mathrm{MeOH}$, r.t., 5 h, $92 \%$; (g) (Boc) ${ }_{2} \mathrm{O}, \mathrm{Et}_{3} \mathrm{~N}$, $\mathrm{MeOH}, 0{ }^{\circ} \mathrm{C}$-r.t., $2 \mathrm{~h}, 95 \%$; (h) (i) $\mathrm{BnO}\left(\mathrm{CH}_{2}\right)_{4} \mathrm{Br}, \mathrm{KI}, \mathrm{NaH}, \mathrm{DMF}, 0{ }^{\circ} \mathrm{C}$-r.t., overnight; (ii) $\mathrm{CH}_{3} \mathrm{I}, 50{ }^{\circ} \mathrm{C}$, 2 h, 35\%; (i) 3M HCl/EtOAc, r.t., 2 h, 94\%; (j) 3-hydroxybenzoic acid, $\mathrm{HOBt}, \mathrm{EDCI}, \mathrm{Et}_{3} \mathrm{~N}, \mathrm{CH}_{2} \mathrm{Cl}_{2}$, $0{ }^{\circ} \mathrm{C}-$ r.t., 2 h, 73\%; (k) H2, Pd/C, $\mathrm{MeOH}$, r.t., 5 h, 92\%; (l) ADDP, TBP, $\mathrm{CH}_{2} \mathrm{Cl}_{2}$, r.t., 4 h, 23\%; (m) $\mathrm{H}_{2}$, $\mathrm{Pd} / \mathrm{C}, \mathrm{MeOH}$, r.t., overnight, 90\%; (n) benzyl 3-hydroxybenzoate, ADDP, TBP, $\mathrm{CH}_{2} \mathrm{Cl}_{2}, 65 \%$; (o) $\mathrm{H}_{2}$, $\mathrm{Pd} / \mathrm{C}, \mathrm{MeOH}$, r.t., 5 h, 95\%; (p) $3 \mathrm{M} \mathrm{HCl} / \mathrm{EtOAc}$, r.t., 2 h, 93\%; (q) $\mathrm{HOBt}, \mathrm{EDCI}, \mathrm{Et}_{3} \mathrm{~N}, \mathrm{CH}_{2} \mathrm{Cl}_{2}, 0{ }^{\circ} \mathrm{C}$-r.t., $1 \mathrm{~h}, 39 \%$.

With the RCM results and the conformational characteristics of the macrocycles, we turned to explore the possibility of macrocyclization using the Mitsunobu protocol. Unfortunately, the macrocyclization of path $b$ failed under various Mitsunobu conditions (Table 2, Entries 1-3). This is due to the fact the pKa values of the protons of both hydroxyl group are bigger than the pKa value of the betaine intermediate during the reaction. On the other hand, the intramolecular Mitsunobu reaction of path $c$ works smoothly and the desired 13-member macrocycle 10a was obtained in a low yield of $7 \%$ using a mixture of triphenylphosphine and diethyl azodicarboxylate (DEAD) (Entry 4). Nevertheless, $N, N, N^{\prime}, N^{\prime}$-tetramethylazodicarboxamide (TMAD) was shown to enhance the reactivity of this nucleophile of $\mathrm{pKa}$ in inactivated systems, leading to higher overall yields (Entry 5). A combination of 1,1'-(azodicarbonyl)dipiperidine (ADDP) with tributyl phosphine (TBP) under argon atmosphere afforded a little better result with a 23\% yield. (Entry 6). However, the desired macrocycle 10a was difficult to isolate from the phosphine oxide formed in the cyclization and was still obtained in low yield. This could also be ascribed to the rigid junction between meta-benzenes and hydroxyproline which limits the rotational freedom of the molecular framework. 
Table 2. Results of macrocyclization by Mitsunobu reactions and amide formation ${ }^{\mathrm{a}}$.

\begin{tabular}{|c|c|c|c|c|}
\hline Entry & Path & Reagents & Time (h) & Yield $(\%)^{b}$ \\
\hline 1 & $\mathrm{~b}$ & $\mathrm{DEAD}, \mathrm{PPh}_{3}$ & 24 & 0 \\
\hline 2 & $\mathrm{~b}$ & TMAD, TBP & 24 & 0 \\
\hline 3 & $\mathrm{~b}$ & ADDP, TBP & 24 & 0 \\
\hline 4 & c & $\mathrm{DEAD}, \mathrm{PPh}_{3}$ & 4 & 10 \\
\hline 5 & c & TMAD, TBP & 4 & 21 \\
\hline 6 & c & ADDP, TBP & 4 & 23 \\
\hline 7 & d & $\mathrm{HOBt}, \mathrm{EDCI}, \mathrm{Et}_{3} \mathrm{~N}$ & 1 & 39 \\
\hline 8 & d & HATU, DIEA & 1 & 39 \\
\hline
\end{tabular}

${ }^{\mathrm{a}}$ Reactions were run on $0.3 \mathrm{mmol} \mathrm{scale;}{ }^{\mathrm{b}}$ Isolated yield.

Excitingly, cyclization of $\mathbf{1 8}$ in path $d$ works well with much higher yield and shorter time under standard amide formation conditions (Entry 7). No significant yield increase was found by using more effective HOAt-based reagent (Entry 8). The results indicate that the softer polymethylene linker between the rigid meta-benzene and hydroxyproline greatly reduces the strain in the ansa-bridged macrocycles and enhance the activity of head-to-tail cyclization. The effective morality of the terminal reactive groups is increased. The structure of $10 \mathrm{a}$ was confirmed by ${ }^{1} \mathrm{H}-\mathrm{NMR},{ }^{13} \mathrm{C}-\mathrm{NMR}$ and $\mathrm{HRMS}$.

We next turned our attention to the reactivity scope of macrocycle $\mathbf{1 0}$. Under amide formation conditions, the formation of 14- and 15-member macrocycles $10 \mathrm{~b}$ and $10 \mathrm{c}$ was achieved in moderate yields of $44 \%$ and $56 \%$, respectively. The macrocyclization of 10 promoted us to reinvestigate the synthesis of 9 using the same macrocyclization strategy. Using trans-4-hydroxy-L-proline and cis-2-butene-1,4-diol as starting materials, macrocycle 9 was successfully obtained after five steps in $25 \%$ yield (Scheme 3 ).

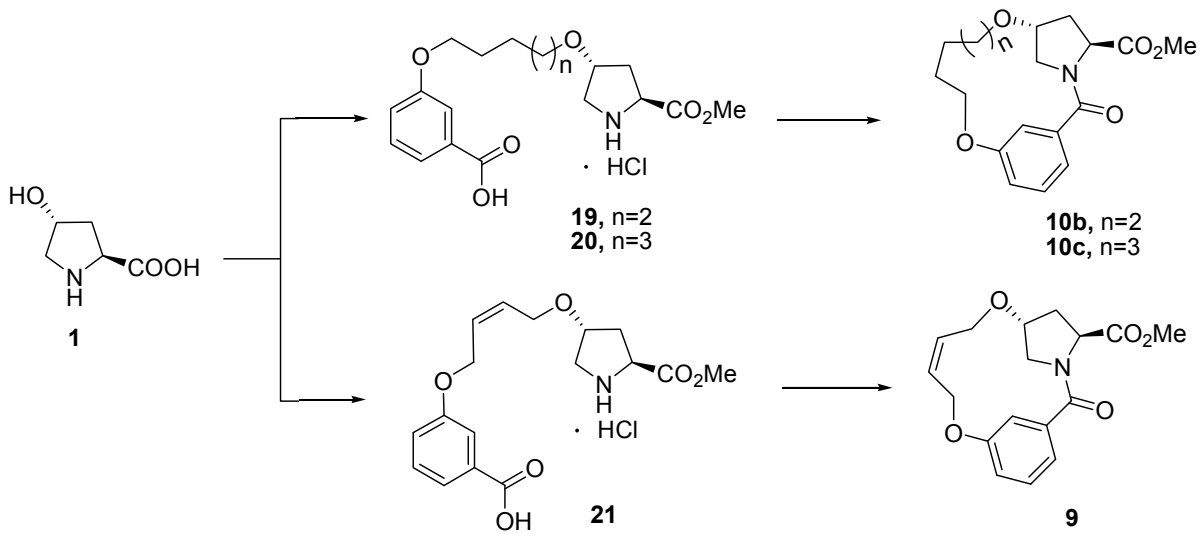

Scheme 3. Synthesis of $8,9 b$ and $9 c$ under amide formation conditions.

The results indicate that the macrocyclization is not influenced by the configuration of the linear chain. Ring size is found to be an important factor that governs the yield of a head-to-tail macrocyclization. The yields of macrocycles increase with the increase of the rings in the range of 13-15 members because the strain energy of cyclization of 13-member macrocycles is much higher than that of 14- and 15-member rings, and the EM value of cyclization of 13-member macrocycles is much lower than that of 14- and 15-member rings.

\subsection{In Vitro Anti-Tumor Screening}

A small library derived from $\mathbf{6 a}-\mathbf{b}, \mathbf{9}$ and $\mathbf{1 0 a}-\mathbf{c}$ was obtained by hydrolysis of the macrocycles and condensation with amines. The anti-tumor activities for lung cancer cell line A549, breast cancer cell line MDA-MB-231 and hepatocarcinoma cell line Hep G2 of all these new compounds were screened 
in vitro by an MTT assay. The $\mathrm{IC}_{50}$ values of the compounds are summarized in Table 3 . Most of the compounds show some inhibitory activities against A549, MDA-MB-231 and Hep G2. Compounds 22-29 where the linker contains a triazole group showed moderate anti-tumor activity with $\mathrm{IC}_{50}$ values of $26.79-48.27 \mu \mathrm{mol} / \mathrm{L}$. Compounds 30-33 containing alkene chains have antiproliferative effects on all three human tumor cell lines with $\mathrm{IC}_{50}$ values near $10 \mu \mathrm{mol} / \mathrm{L}$, in particular compound 33 which showed the best activity against $\mathrm{A} 549$ cells with an $\mathrm{IC}_{50}$ value of $2.55 \mu \mathrm{mol} / \mathrm{L}$, much better than the reference drug cisplatin with an $\mathrm{IC}_{50}$ value of $15.42 \mu \mathrm{mol} / \mathrm{L}$. However, compounds 34-45 containing alkyl chains showed weaker anti-tumor activity than compounds 30-33. In the future, further structure-activity relationship studies will be performed to determine how the substituents affected the anti-tumor activity and to design the best chemical structure in the future.

Table 3. Anti-tumor activities of macrocycles.

\begin{tabular}{|c|c|c|c|c|c|}
\hline \multirow{2}{*}{\multicolumn{2}{|c|}{ Compound }} & \multirow{2}{*}{$\mathbf{R}$} & \multicolumn{3}{|c|}{$\mathrm{IC}_{50}(\mu \mathrm{mol} / \mathrm{L})$} \\
\hline & & & \multirow{2}{*}{$\begin{array}{l}\text { A549 } \\
32.24\end{array}$} & \multicolumn{2}{|c|}{ MDA-MB-231 Hep G2 } \\
\hline & 22 & $\mathrm{OH}$ & & 45.14 & 44.17 \\
\hline & 23 & $\mathrm{NH}_{2}$ & 26.79 & 29.94 & 37.28 \\
\hline & 24 & $\mathrm{NHPh}$ & 45.73 & 35.58 & 46.26 \\
\hline & 25 & $\mathrm{NHCH}_{2} \mathrm{CH}\left(\mathrm{CH}_{3}\right)_{2}$ & 37.73 & 42.47 & 48.27 \\
\hline & 26 & $\mathrm{OH}$ & 37.11 & 34.28 & 44.88 \\
\hline & 27 & $\mathrm{NH}_{2}$ & 41.28 & 27.99 & 34.71 \\
\hline & 28 & $\mathrm{NHPh}$ & 46.29 & 43.68 & 36.28 \\
\hline & 29 & $\mathrm{NHCH}_{2} \mathrm{CH}\left(\mathrm{CH}_{3}\right)_{2}$ & 32.18 & 43.19 & 37.31 \\
\hline & 30 & $\mathrm{OH}$ & 11.23 & 10.26 & 23.21 \\
\hline & 31 & $\mathrm{NH}_{2}$ & 5.21 & 12.33 & 31.94 \\
\hline & 32 & $\mathrm{NHPh}$ & 4.76 & 9.67 & 26.26 \\
\hline & 33 & $\mathrm{NHCH}_{2} \mathrm{CH}\left(\mathrm{CH}_{3}\right)_{2}$ & 2.55 & 11.87 & 41.10 \\
\hline & 34 & $\mathrm{OH}$ & $>100$ & 96.15 & 96.16 \\
\hline & 35 & $\mathrm{NH}_{2}$ & 89.54 & 90.54 & 91.47 \\
\hline & 36 & $\mathrm{NHPh}$ & 54.31 & 85.32 & 95.39 \\
\hline & 37 & $\mathrm{NHCH}_{2} \mathrm{CH}\left(\mathrm{CH}_{3}\right)_{2}$ & 77.93 & 86.27 & 73.06 \\
\hline & 38 & $\mathrm{OH}$ & $>100$ & 92.34 & $>100$ \\
\hline & 39 & $\mathrm{NH}_{2}$ & 63.74 & 57.33 & $>100$ \\
\hline & 40 & $\mathrm{NHPh}$ & 87.99 & 76.36 & 68.39 \\
\hline & 41 & $\mathrm{NHCH}_{2} \mathrm{CH}\left(\mathrm{CH}_{3}\right)_{2}$ & 34.91 & 47.28 & $>100$ \\
\hline & 42 & $\mathrm{OH}$ & $>100$ & $>100$ & 87.39 \\
\hline & 43 & $\mathrm{NH}_{2}$ & 69.74 & 65.96 & 64.88 \\
\hline & 44 & $\mathrm{NHPh}$ & 98.24 & 23.11 & 88.13 \\
\hline & 45 & $\mathrm{NHCH}_{2} \mathrm{CH}\left(\mathrm{CH}_{3}\right)_{2}$ & 93.57 & 88.69 & 89.58 \\
\hline & Cisplatin & & 15.42 & 19.68 & 17.35 \\
\hline
\end{tabular}

\section{Materials and Methods}

\subsection{General Information}

Pentamethylcyclopentadienylbis(triphenylphosphine)ruthenium(II) chloride [Cp* $\left.\mathrm{RuCl}\left(\mathrm{PPh}_{3}\right)_{2}\right]$, diethyl azodicarboxylate (DEAD), tri- $n$-butylphosphine (TBP), $N, N, N^{\prime}, N^{\prime}$-tetramethylazo-dicarboxamide (TMAD) and 1,1-(azodicarbonyl)-dipiperidine (ADDP), $\mathrm{N}$-[(dimethylamino)-H-1,2,3-triazolo[4,5b]pyridin-1-yl-methylene]- $N$-methylmethanaminium hexafluorophosphate (HATU) were purchased from Aldrich Chemical Company (Shanghai, China). Toluene was dried overnight over calcium chloride, filtered and distilled from sodium/benzophenone ketyl and degassed by three evacuation/ refill cycles under Ar before use. Unless stated otherwise, other reagents and solvents were all purchased from commercial suppliers and were used without further purification. All reactions 
were monitored by TLC. Chromatography refers to open column chromatography (200-300 mesh). Melting points were recorded on a RY-1 microscopic melting apparatus (Tianjin, China) and are uncorrected. ${ }^{1} \mathrm{H}-\mathrm{NMR}$ and ${ }^{13} \mathrm{C}-\mathrm{NMR}$ spectra were recorded on Bruker $500 \mathrm{MHz}$ and $125 \mathrm{~Hz}$ instruments (Bruker, Rheinstetten, Germany). Chemical shifts were reported in parts per million $\delta$ relative to tetramethylsilane. Mass spectra were performed on an Ultima Global spectrometer (Waters Corporation, Worcester, MA, USA) equipped with an ESI source.

\subsection{Synthesis}

3.2.1. Procedure for the Preparation of Methyl (12R,14S)-16-Oxo-2,11-dioxa-5,6,7,15-tetraazatetracyclo[15.3.1.1 $1^{12,15} \cdot 0^{5,9}$ ]docosane-6,8,1(21),17,19-pentaene-14-carboxylate (6a)

A solution of compound $5(0.11 \mathrm{~g}, 0.3 \mathrm{mmol})$ and copper(I) iodide $(2.1 \mathrm{mg}, 0.015 \mathrm{mmol})$ in anhydrous toluene $(15 \mathrm{~mL})$ was stirred at reflux under argon atmosphere for 2 hours. The solvent was removed under reduced pressure and the residue was subjected to column chromatography on silica gel (100-200 mesh) using petroleum/ethyl acetate as eluent to afford 1,4-disubstituted 1,2,3-triazole 6a $(0.061 \mathrm{~g}, 55 \%)$. The physical and spectral data for compound $6 \mathbf{6}$ are listed below. ${ }^{1} \mathrm{H}-\mathrm{NMR}$ and ${ }^{13} \mathrm{C}-\mathrm{NMR}$ spectra are provided in the Supplementary Materials. White solid, m.p. $186-189{ }^{\circ} \mathrm{C} ;{ }^{1} \mathrm{H}-\mathrm{NMR}$ $\left(-\mathrm{CDCl}_{3}\right): \delta 7.74(\mathrm{~s}, 1 \mathrm{H}), 7.25(\mathrm{t}, 1 \mathrm{H}, J=7.9 \mathrm{~Hz}), 6.98\left(\mathrm{dd}, 1 \mathrm{H}, J_{1}=2.2 \mathrm{~Hz}, J_{2}=8.3 \mathrm{~Hz}\right), 6.91(\mathrm{~d}, 1 \mathrm{H}$, $J=7.4 \mathrm{~Hz}), 6.21(\mathrm{~s}, 1 \mathrm{H}), 4.95(\mathrm{~d}, 1 \mathrm{H}, J=14.1 \mathrm{~Hz}), 4.83-4.77(\mathrm{~m}, 3 \mathrm{H}), 4.57-4.53(\mathrm{~m}, 1 \mathrm{H}), 4.49-4.44(\mathrm{~m}$, $2 \mathrm{H}), 4.23-4.22(\mathrm{~m}, 1 \mathrm{H}), 3.78(\mathrm{~s}, 3 \mathrm{H}), 3.24-3.17(\mathrm{~m}, 2 \mathrm{H}), 2.53-2.48(\mathrm{~m}, 1 \mathrm{H}), 2.14-2.10(\mathrm{~m}, 1 \mathrm{H}) ;{ }^{13} \mathrm{C}-\mathrm{NMR}$ $\left(-\mathrm{CDCl}_{3}\right): \delta 172.7,169.9,158.8,145.5,137.5,130.5,124.2,119.8,119.3,111.4,80.2,68.3,64.5,56.7,55.0$, 52.3, 51.8, 37.5; HRMS (ESI-TOF ${ }^{+}$): $m / z$ Calcd. for $\mathrm{C}_{18} \mathrm{H}_{21} \mathrm{~N}_{4} \mathrm{O}_{5}[\mathrm{M}+\mathrm{H}]^{+}:$373.1512. Found: 373.1514 .

3.2.2. Procedure for the Preparation of Methyl (11R,13S)-15-Oxo-2,10-dioxa-5,6,7,14-tetraazatetracyclo[14.3.1.1 ${ }^{5,8} \cdot 1^{11,14}$ ]docosane-6,8(21),1(20),16,18-pentaene-13-carboxylate (6b)

A solution of compound $5(0.11 \mathrm{~g}, 0.3 \mathrm{mmol})$ and $\left[\mathrm{Cp}^{*} \mathrm{RuCl}\right]_{4}(0.016 \mathrm{~g}, 0.015 \mathrm{mmol})$ in anhydrous toluene $(15 \mathrm{~mL})$ was stirred at $80{ }^{\circ} \mathrm{C}$ under argon atmosphere for 4 hours. The solvent was removed under reduced pressure and the resulting residue was purified by column chromatography with petroleum/ethyl acetate as eluting solvent to afford $\mathbf{6 b}(0.054 \mathrm{~g}, 48 \%)$. The physical and spectral data for compound $\mathbf{6 b}$ are listed below. ${ }^{1} \mathrm{H}-\mathrm{NMR}$ and ${ }^{13} \mathrm{C}-\mathrm{NMR}$ spectra are provided in the Supplementary Materials. White solid, m.p. 203-205 ${ }^{\circ} \mathrm{C} ;{ }^{1} \mathrm{H}-\mathrm{NMR}\left(\mathrm{CDCl}_{3}\right): \delta 7.74(\mathrm{~s}, 1 \mathrm{H}), 7.42(\mathrm{t}, 1 \mathrm{H}, J=7.9 \mathrm{~Hz}), 7.22$ $(\mathrm{d}, 1 \mathrm{H}, J=7.5 \mathrm{~Hz}), 7.07\left(\mathrm{dd}, 1 \mathrm{H}, J_{1}=2.3 \mathrm{~Hz}, J_{2}=8.7 \mathrm{~Hz}\right), 7.00(\mathrm{~s}, 1 \mathrm{H}), 5.10-5.04(\mathrm{~m}, 1 \mathrm{H}), 4.94-4.91$ $(\mathrm{m}, 1 \mathrm{H}), 4.74(\mathrm{~d}, 1 \mathrm{H}, J=11.5 \mathrm{~Hz}), 4.62-4.55(\mathrm{~m}, 2 \mathrm{H}), 4.42(\mathrm{~d}, 1 \mathrm{H}, J=11.5 \mathrm{~Hz}), 4.36-4.31(\mathrm{~m}, 1 \mathrm{H}), 4.22-4.21$ $(\mathrm{m}, 1 \mathrm{H}), 4.04(\mathrm{~d}, 1 \mathrm{H}, J=13.6 \mathrm{~Hz}), 3.82(\mathrm{~s}, 3 \mathrm{H}), 3.52\left(\mathrm{dd}, 1 \mathrm{H}, J_{1}=2.9 \mathrm{~Hz}, J_{2}=12.7 \mathrm{~Hz}\right), 2.64-2.59(\mathrm{~m}, 1 \mathrm{H})$, 2.41-2.36 (m, 1H). ${ }^{13} \mathrm{C}-\mathrm{NMR}\left(\mathrm{CDCl}_{3}\right): \delta 172.5,169.9,137.9,134.1,132.9,131.3,120.3,119.6,109.9,79.0$, 64.6, 59.9, 56.4, 54.4, 53.4, 52.5, 43.4, 36.6. HRMS (ESI-TOF ${ }^{+}$): $m / z$ Calcd. for $\mathrm{C}_{18} \mathrm{H}_{21} \mathrm{~N}_{4} \mathrm{O}_{5}[\mathrm{M}+\mathrm{H}]^{+}$: 373.1512. Found: 373.1521 .

3.2.3. General Procedure for the Preparation of Methyl $(4 Z, 8 R, 10 S)-12-O x o-2,7-d i o x a-11-a z a-t r i c y c l o$ [11.3.1.1 ${ }^{8,11}$ ]octadecane-4,1(17),13,15-tetraene-10-carboxylate (9) and Compounds 10a-c

To a solution of 18-21 $(0.3 \mathrm{mmol})$ in dichloromethane $(15 \mathrm{~mL})$, HOBt $(0.36 \mathrm{mmol})$ was added slowly followed by EDCI $(0.36 \mathrm{mmol})$ at $0{ }^{\circ} \mathrm{C}$ After stirring at r.t. for half an hour, a solution of triethylamine $(0.75 \mathrm{mmol})$ in dichloromethane $(2 \mathrm{~mL})$ was added dropwise at $0{ }^{\circ} \mathrm{C}$. Then the mixture was stirred at r.t. for half an hour. After adding $10 \mathrm{~mL}$ of water, the mixture was extracted with dichloromethane $(3 \times 5 \mathrm{~mL})$. The combined organic extracts were dried over anhydrous sodium sulfate and concentrated in vacuo. The residue was subjected to column chromatography on silica gel (100-200 mesh) using petroleum/ethyl acetate as eluent to afford $\mathbf{9}$ and 10a-c, with yields ranging from $25 \%$ to $56 \%$. The physical and spectral data for compounds 9 and $10 \mathbf{a}-\mathbf{c}$ are listed below. ${ }^{1} \mathrm{H}-\mathrm{NMR}$ and ${ }^{13} \mathrm{C}-\mathrm{NMR}$ spectra are provided in the Supplementary Materials. 
9: Yellow oil, yield 25\%, ${ }^{1} \mathrm{H}-\mathrm{NMR}\left(\mathrm{CDCl}_{3}\right): \delta 7.23(\mathrm{t}, 1 \mathrm{H}, J=7.9 \mathrm{~Hz}), 7.07(\mathrm{~d}, 1 \mathrm{H}, J=7.4 \mathrm{~Hz}), 6.94(\mathrm{~s}, 1 \mathrm{H})$, $6.84(\mathrm{~d}, 1 \mathrm{H}, J=8.0 \mathrm{~Hz}), 5.76-5.72(\mathrm{~m}, 1 \mathrm{H}), 5.68-5.66(\mathrm{~m}, 1 \mathrm{H}), 4.74(\mathrm{~s}, 1 \mathrm{H}, J=8.2 \mathrm{~Hz}), 4.39(\mathrm{~d}, 2 \mathrm{H}, J=6.0 \mathrm{~Hz})$, 4.07-4.03 (m, 1H), 3.99-3.90 (m, 2H), $3.71(\mathrm{~s}, 3 \mathrm{H}), 3.64-3.52(\mathrm{~m}, 2 \mathrm{H}), 2.42-2.38(\mathrm{~m}, 1 \mathrm{H}), 2.06-2.02$ (m, 1H). ${ }^{13} \mathrm{C}-\mathrm{NMR}\left(\mathrm{CDCl}_{3}\right): \delta 172.7,169.6,158.2,140.0,129.5,128.0,119.9,116.9,113.3,64.8,63.8,57.7$, 54.3, 52.4, 35.2.; HRMS (ESI-TOF ${ }^{+}$): $m / z$ Calcd. for $\mathrm{C}_{17} \mathrm{H}_{20} \mathrm{NO}_{5}[\mathrm{M}+\mathrm{H}]^{+}: 318.1341$. Found: 318.1343.

Methyl (8R,10S)-12-oxo-2,7-dioxa-11-aza-tricyclo[11.3.1.1,11 ]octadecane-1(17),13,15-triene-10-carboxylate (10a): White solid, m.p. $142-144{ }^{\circ} \mathrm{C}$, yield 39\%, ${ }^{1} \mathrm{H}-\mathrm{NMR}\left(\mathrm{CDCl}_{3}\right): \delta 7.26(\mathrm{t}, 1 \mathrm{H}, J=8.2 \mathrm{~Hz}), 7.09(\mathrm{~d}, 1 \mathrm{H}$, $J=7.4 \mathrm{~Hz}), 7.01(\mathrm{~s}, 1 \mathrm{H}), 6.84\left(\mathrm{dd}, 1 \mathrm{H}, J_{1}=2.3 \mathrm{~Hz}, J_{2}=8.3 \mathrm{~Hz}\right), 4.85(\mathrm{t}, 1 \mathrm{H}, J=8.5 \mathrm{~Hz}), 4.01(\mathrm{br}, 1 \mathrm{H})$, 3.87-3.82 (m, 2H), $3.77(\mathrm{~s}, 3 \mathrm{H}), 3.64(\mathrm{~s}, 2 \mathrm{H}), 3.54-3.48(\mathrm{~m}, 1 \mathrm{H}), 3.26-3.24(\mathrm{~m}, 1 \mathrm{H}), 2.48-2.44(\mathrm{~m}, 1 \mathrm{H})$, 2.11-2.05 (m, 1H), 1.76-1.67 (m, 2H), 1.64-1.62 (m, 2H). ${ }^{13} \mathrm{C}-\mathrm{NMR}\left(\mathrm{CDCl}_{3}\right) \delta 172.8,170.0,158.7,137.0$, 129.2, 119.4, 117.0, 112.6, 68.4, 67.5, 57.6, 54.8, 52.3, 35.3, 26.3, 25.8.; HRMS (ESI-TOF ${ }^{+}$): $m / z$ Calcd. for $\mathrm{C}_{17} \mathrm{H}_{22} \mathrm{NO}_{5}[\mathrm{M}+\mathrm{H}]^{+}:$320.1498. Found: 320.1505 .

Methyl (9R,11S)-13-oxo-2,8-dioxa-12-aza-tricyclo[12.3.1.19,12]nonadecane-1(18),14,16-triene-11-carboxylate (10b): Yellow oil, yield 44\%, ${ }^{1} \mathrm{H}-\mathrm{NMR}\left(\mathrm{CDCl}_{3}\right): \delta 7.18(\mathrm{t}, 1 \mathrm{H}, J=7.8 \mathrm{~Hz}), 7.01(\mathrm{~d}, 1 \mathrm{H}, J=7.6 \mathrm{~Hz}), 6.98$ $(\mathrm{s}, 1 \mathrm{H}), 6.85(\mathrm{~d}, 1 \mathrm{H}, J=8.0 \mathrm{~Hz}), 4.68(\mathrm{t}, 1 \mathrm{H}, J=8.1 \mathrm{~Hz}), 3.97(\mathrm{br}, 1 \mathrm{H}), 3.89-3.85(\mathrm{~m}, 1 \mathrm{H}), 3.83-3.80$ $(\mathrm{m}, 1 \mathrm{H}), 3.69(\mathrm{~s}, 3 \mathrm{H}), 3.65\left(\mathrm{dd}, 1 \mathrm{H}, J_{1}=4.0 \mathrm{~Hz}, J_{2}=11.5 \mathrm{~Hz}\right), 3.47(\mathrm{~d}, 1 \mathrm{H}, J=11.3 \mathrm{~Hz}), 3.38-3.36(\mathrm{~m}, 1 \mathrm{H})$, 3.19-3.14 (m, 1H), $2.37(\mathrm{t}, 1 \mathrm{H}, J=10.5 \mathrm{~Hz}), 2.03-1.97(\mathrm{~m}, 1 \mathrm{H}), 1.68-1.64(\mathrm{~m}, 2 \mathrm{H}), 1.49-1.44(\mathrm{~m}, 2 \mathrm{H})$, 1.42-1.38 (m, 2H). ${ }^{13} \mathrm{C}-\mathrm{NMR}\left(\mathrm{CDCl}_{3}\right): \delta 172.6,169.9,158.9,136.8,129.1,119.3,117.5,112.0,68.7,67.7$, 57.7, 54.9, 52.2, 34.6, 29.3, 28.8, 22.8.; HRMS (ESI-TOF ${ }^{+}$): $m / z$ Calcd. for $\mathrm{C}_{18} \mathrm{H}_{24} \mathrm{NO}_{5}[\mathrm{M}+\mathrm{H}]^{+}: 334.1654$. Found: 334.1653 .

Methyl (10R,12S)-14-oxo-2,9-dioxa-13-aza-tricyclo[13.3.1.1 10,13] eicosane-1(19),15,17-triene-12-carboxylate (10c) Yellow oil, yield 54\%, ${ }^{1} \mathrm{H}-\mathrm{NMR}\left(\mathrm{CDCl}_{3}\right): \delta 7.21(\mathrm{t}, 1 \mathrm{H}, J=7.8 \mathrm{~Hz}), 7.03(\mathrm{~d}, 1 \mathrm{H}, J=7.6 \mathrm{~Hz}), 7.00$ $(\mathrm{s}, 1 \mathrm{H}), 6.85\left(\mathrm{dd}, 1 \mathrm{H}, J_{1}=2.0 \mathrm{~Hz}, J_{2}=8.3 \mathrm{~Hz}\right), 4.73(\mathrm{t}, 1 \mathrm{H}, J=8.2 \mathrm{~Hz}), 3.96(\mathrm{br}, 1 \mathrm{H}), 3.87-3.83(\mathrm{~m}, 2 \mathrm{H})$, $3.71(\mathrm{~s}, 3 \mathrm{H}), 3.63-3.60(\mathrm{~m}, 1 \mathrm{H}), 3,54-3.51(\mathrm{~m}, 1 \mathrm{H}), 3.38-3.35(\mathrm{~m}, 1 \mathrm{H}), 3.16-3.12(\mathrm{~m}, 1 \mathrm{H}), 2.36(\mathrm{t}, 1 \mathrm{H}$, $J=10.0 \mathrm{~Hz}), 2.04-1.98(\mathrm{~m}, 1 \mathrm{H}), 1.67-1.63(\mathrm{~m}, 2 \mathrm{H}), 1.46-1.41(\mathrm{~m}, 3 \mathrm{H}), 1.34-1.30(\mathrm{~m}, 3 \mathrm{H}) .{ }^{13} \mathrm{C}-\mathrm{NMR}$ $\left(\mathrm{CDCl}_{3}\right): \delta 172.7,169.9,158.9,136.9,129.2,119.3,116.8,112.9,68.8,67.8,57.7,54.7,52.3,35.1,29.5,29.0$, 25.8, 25.6.; HRMS (ESI-TOF ${ }^{+}$): $m / z$ Calcd. for $\mathrm{C}_{19} \mathrm{H}_{26} \mathrm{NO}_{5}[\mathrm{M}+\mathrm{H}]^{+}$: 348.1811. Found: 348.1813 .

\subsubsection{General Procedure for the Preparation of Compounds 22-45}

To a suspension of macrocyclic ester $\mathbf{6 a}-\mathbf{b}, \mathbf{9}$ or $10 \mathbf{a}-\mathbf{c}(1 \mathrm{mmol})$ in methanol $(2 \mathrm{~mL})$, a solution of $\mathrm{NaOH}(4.8 \mathrm{mg}, 1.2 \mathrm{mmol})$ in water $(0.5 \mathrm{~mL})$ was added slowly. After stirring at r.t. for $3 \mathrm{~h}$, the mixture was evaporated to remove solvent and acidified with $3 \mathrm{~N} \mathrm{HCl}$ to $\mathrm{pH}=3$, the precipitated product 22, 26, 30, 34, 38 or 42 was isolated by filtration and dried under reduced pressure.

To a solution of macrocyclic acid 22, 26, 30, 34, 38 or $42(0.1 \mathrm{mmol})$ in dichloromethane $(0.5 \mathrm{~mL})$, HOBt $(0.15 \mathrm{mmol})$ was added slowly followed by EDCI $(0.15 \mathrm{mmol})$ at $0{ }^{\circ} \mathrm{C}$ After stirring at r.t. for half an hour, a solution of amine $(0.12 \mathrm{mmol})$ and triethylamine $(0.25 \mathrm{mmol})$ in dichloromethane $(0.2 \mathrm{~mL})$ was added dropwise at $0{ }^{\circ} \mathrm{C}$. Then the mixture was stirred at r.t. for $1 \mathrm{~h}$. After adding $1 \mathrm{~mL}$ of water, the mixture was extracted with dichloromethane $(3 \times 0.3 \mathrm{~mL})$. The combined organic extracts were dried over anhydrous sodium sulfate and concentrated in vacuo. The residue was subjected to column chromatography on silica gel (100-200 mesh) using petroleum/ethyl acetate as eluent to afford macrocyclic amide $23-25,27-29,31-33,35-37,39-41$ or $43-45$. The physical and spectral data for compounds 22-45 are listed below. ${ }^{1} \mathrm{H}-\mathrm{NMR}$ spectra are provided in the Supplementary Materials.

(11R,13S)-15-Oxo-2,10-dioxa-5,6,7,14-tetraaza-tetracyclo[14.3.1.1 $\left.1^{5,8} .1^{11,14}\right]$ docosane-6,8(21),1(20),16,18pentaene-13-carboxylic acid (22): White solid, m.p. $210-212{ }^{\circ} \mathrm{C}$, yield $91 \%,{ }^{1} \mathrm{H}-\mathrm{NMR}$ (DMSO- $d_{6}$ ): $\delta 8.24$ $(\mathrm{s}, 1 \mathrm{H}), 7.23(\mathrm{t}, 1 \mathrm{H}, J=7.8 \mathrm{~Hz}), 6.93(\mathrm{~d}, 1 \mathrm{H}, J=7.4 \mathrm{~Hz}), 6.64(\mathrm{~d}, 1 \mathrm{H}, J=7.2 \mathrm{~Hz}), 6.07(\mathrm{~s}, 1 \mathrm{H}), 4.89-4.86$ $(\mathrm{m}, 1 \mathrm{H}), 4.84-4.82(\mathrm{~m}, 1 \mathrm{H}), 4.65(\mathrm{~s}, 2 \mathrm{H}), 4.38-4.20(\mathrm{~m}, 4 \mathrm{H}), 3.07-3.04(\mathrm{~m}, 1 \mathrm{H}), 2.95-2.93(\mathrm{~m}, 1 \mathrm{H})$, 2.35-2.31 (m, 1H), 2.03-1.98 (m, 1H). HRMS (ESI-TOF $\left.{ }^{+}\right): m / z$ Calcd. for $\mathrm{C}_{17} \mathrm{H}_{19} \mathrm{~N}_{4} \mathrm{O}_{5}[\mathrm{M}+\mathrm{H}]^{+}$: 359.1355. Found: 359.1364 . 
(11R,13S)-15-Oxo-2,10-dioxa-5,6,7,14-tetraaza-tetracyclo[14.3.1.1.15.8.11,14]docosane-6,8(21),1(20),16,18pentaene-13-carboxamide (23): White solid, m.p. $257-259{ }^{\circ} \mathrm{C}$, yield $75 \%,{ }^{1} \mathrm{H}-\mathrm{NMR}$ (DMSO- $d_{6}$ ): $\delta 8.18$ $(\mathrm{s}, 1 \mathrm{H}), 7.40-6.81(\mathrm{~m}, 4 \mathrm{H}), 6.09(\mathrm{~s}, 1 \mathrm{H}), 6.64(\mathrm{~d}, 1 \mathrm{H}, J=7.2 \mathrm{~Hz}), 5.75(\mathrm{~s}, 1 \mathrm{H}), 4.91-4.90(\mathrm{~m}, 1 \mathrm{H})$, $4.82-4.79(\mathrm{~m}, 1 \mathrm{H}), 4.64(\mathrm{~s}, 2 \mathrm{H}), 4.41-4.15(\mathrm{~m}, 4 \mathrm{H}), 3.14-3.12(\mathrm{~m}, 1 \mathrm{H}), 2.96-2.94(\mathrm{~m}, 1 \mathrm{H}), 2.25-2.24$ $(\mathrm{m}, 1 \mathrm{H}), 1.98-1.94(\mathrm{~m}, 1 \mathrm{H})$. HRMS $\left(\right.$ ESI-TOF $\left.{ }^{+}\right): m / z$ Calcd. for $\mathrm{C}_{17} \mathrm{H}_{20} \mathrm{~N}_{5} \mathrm{O}_{4}[\mathrm{M}+\mathrm{H}]^{+}: 358.1515$. Found: 358.1512.

(11R,13S)-15-Oxo-N-phenyl-2,10-dioxa-5,6,7,14-tetraaza-tetracyclo[14.3.1.1 $\left.1^{5,8} \cdot 1^{11,14}\right]$ docosane-6,8(21),1(20), 16,18-pentaene-13-carboxamide (24): White solid, m.p. $258-260{ }^{\circ} \mathrm{C}$, yield $82 \%,{ }^{1} \mathrm{H}-\mathrm{NMR}\left(\mathrm{CDCl}_{3}\right): \delta 9.57$ $(\mathrm{s}, 1 \mathrm{H}), 7.40-6.81(\mathrm{~m}, 4 \mathrm{H}), 7.59(\mathrm{~s}, 1 \mathrm{H}), 7.55-7.53(\mathrm{~m}, 2 \mathrm{H}), 7.31-7.21(\mathrm{~m}, 3 \mathrm{H}), 7.08(\mathrm{t}, 1 \mathrm{H}, J=7.5 \mathrm{~Hz}), 7.02$ $(\mathrm{d}, 1 \mathrm{H}, J=7.9 \mathrm{~Hz}), 6.76(\mathrm{~d}, 1 \mathrm{H}, J=7.3 \mathrm{~Hz}), 6.31(\mathrm{~s}, 1 \mathrm{H}), 5.00(\mathrm{t}, 1 \mathrm{H}, J=7.3 \mathrm{~Hz}), 4.91(\mathrm{~d}, 1 \mathrm{H}, J=14.0 \mathrm{~Hz})$, $4.81-4.78(\mathrm{~m}, 2 \mathrm{H}), 4.57-4.55(\mathrm{~m}, 2 \mathrm{H}), 4.38(\mathrm{~d}, 1 \mathrm{H}, \mathrm{J}=14.1 \mathrm{~Hz}), 4.25-4.24(\mathrm{~m}, 1 \mathrm{H}), 3.37-3.21(\mathrm{~m}, 2 \mathrm{H})$, 2.93-2.91 (m, 1H), 2.27-2.22 (m, 1H). HRMS (ESI-TOF $\left.{ }^{+}\right): m / z$ Calcd. for $\mathrm{C}_{23} \mathrm{H}_{24} \mathrm{~N}_{5} \mathrm{O}_{4}[\mathrm{M}+\mathrm{H}]^{+}$: 434.1828. Found: 434.1822.

(11R,13S)-15-Oxo-N-isobutyl-2,10-dioxa-5,6,7,14-tetraaza-tetracyclo[14.3.1.1 $\left.1^{5,8} \cdot 1^{11,14}\right]$ docosane-6,8(21),1(20), 16,18-pentaene-13-carboxamide (25): White solid, m.p. $270-272{ }^{\circ} \mathrm{C}$, yield $79 \%,{ }^{1} \mathrm{H}-\mathrm{NMR}\left(\mathrm{CDCl}_{3}\right): \delta 7.56$ $(\mathrm{s}, 1 \mathrm{H}), 7.31(\mathrm{~s}, 1 \mathrm{H}), 7.23-7.22(\mathrm{~m}, 1 \mathrm{H}), 7.01(\mathrm{~d}, 1 \mathrm{H}, J=7.6 \mathrm{~Hz}), 6.74(\mathrm{~d}, 1 \mathrm{H}, J=7.2 \mathrm{~Hz}), 6.29(\mathrm{~s}, 1 \mathrm{H})$, $4.90-4.79(\mathrm{~m}, 4 \mathrm{H}), 4.55-4.54(\mathrm{~m}, 2 \mathrm{H}), 4.36(\mathrm{~d}, 1 \mathrm{H}, J=14.1 \mathrm{~Hz}), 4.20(\mathrm{~s}, 1 \mathrm{H}), 3.31-3.28(\mathrm{~m}, 1 \mathrm{H}), 3.20-3.15$ $(\mathrm{m}, 2 \mathrm{H}), 3.04-3.01(\mathrm{~m}, 1 \mathrm{H}), 2.85-2.80(\mathrm{~m}, 1 \mathrm{H}), 2.20-2.16(\mathrm{~m}, 1 \mathrm{H}), 1.79-1,76(\mathrm{~m}, 1 \mathrm{H}), 0.89(\mathrm{~d}, 6 \mathrm{H}, J=6.3 \mathrm{~Hz})$. HRMS (ESI-TOF ${ }^{+}$): $m / z$ Calcd. for $\mathrm{C}_{21} \mathrm{H}_{28} \mathrm{~N}_{5} \mathrm{O}_{4}[\mathrm{M}+\mathrm{H}]^{+}:$414.2141. Found: 414.2135.

(12R,14S)-16-Oxo-2,11-dioxa-5,6,7,15-tetraaza-tetracyclo[15.3.1.1 12,15. $\left.0^{5,9}\right]$ docosane-6,8,1(21),17,19-pentaene14-carboxylic acid (26): White solid, m.p. 222-225 ${ }^{\circ} \mathrm{C}$, yield 90\%, ${ }^{1} \mathrm{H}-\mathrm{NMR}$ (DMSO- $\left.d_{6}\right): \delta 7.83(\mathrm{~s}, 1 \mathrm{H}$ ), $7.44(\mathrm{t}, 1 \mathrm{H}, J=7.8 \mathrm{~Hz}), 7.09(\mathrm{~d}, 1 \mathrm{H}, J=8.2 \mathrm{~Hz}), 7.04(\mathrm{~d}, 1 \mathrm{H}, J=7.3 \mathrm{~Hz}), 6.82(\mathrm{~s}, 1 \mathrm{H}), 4.89-4.83(\mathrm{~m}, 1 \mathrm{H})$, $4.73-4.65(\mathrm{~m}, 3 \mathrm{H}), 4.56-4.49(\mathrm{~m}, 2 \mathrm{H}), 4.36-4.32(\mathrm{~m}, 1 \mathrm{H}), 4.26-4.25(\mathrm{~m}, 1 \mathrm{H}), 4.02-4.00(\mathrm{~m}, 1 \mathrm{H}), 3.28-3.26$ $(\mathrm{m}, 1 \mathrm{H}), 2.47-2.42(\mathrm{~m}, 1 \mathrm{H}), 2.30-2.26(\mathrm{~m}, 1 \mathrm{H})$. HRMS (ESI-TOF $\left.{ }^{+}\right): \mathrm{m} / z$ Calcd. for $\mathrm{C}_{17} \mathrm{H}_{19} \mathrm{~N}_{4} \mathrm{O}_{5}[\mathrm{M}+\mathrm{H}]^{+}$: 359.1355. Found: 359.1346.

(12R,14S)-16-Oxo-2,11-dioxa-5,6,7,15-tetraaza-tetracyclo[15.3.1.1 ${ }^{12,15} \cdot 0^{5,9}$ ]docosane-6,8,1(21),17,19-pentaene14-carboxamide (27): White solid, m.p. $258-260{ }^{\circ} \mathrm{C}$, yield 77\%, ${ }^{1} \mathrm{H}-\mathrm{NMR}$ (DMSO- $d_{6}$ ): $\delta 7.82(\mathrm{~s}, 1 \mathrm{H}), 7.50$ $(\mathrm{s}, 1 \mathrm{H}), 7.44(\mathrm{t}, 1 \mathrm{H}, J=7.8 \mathrm{~Hz}), 7.12-7.08(\mathrm{~s}, 3 \mathrm{H}), 6.76(\mathrm{~s}, 1 \mathrm{H}), 4.85-4.83(\mathrm{~m}, 1 \mathrm{H}), 4.70-4.58(\mathrm{~m}, 3 \mathrm{H})$, $4.52-4.51(\mathrm{~m}, 2 \mathrm{H}), 4.38-4.37(\mathrm{~m}, 1 \mathrm{H}), 4.21(\mathrm{~s}, 1 \mathrm{H}), 3.92-3.90(\mathrm{~m}, 1 \mathrm{H}), 3.29-3.26(\mathrm{~m}, 1 \mathrm{H}), 2.34-2.25$ $(\mathrm{m}, 2 \mathrm{H})$. HRMS (ESI-TOF $\left.{ }^{+}\right): m / z$ Calcd. for $\mathrm{C}_{17} \mathrm{H}_{20} \mathrm{~N}_{5} \mathrm{O}_{4}[\mathrm{M}+\mathrm{H}]^{+}: 358.1515$. Found: 358.1516.

(12R,14S)-16-Oxo-N-phenyl-2,11-dioxa-5,6,7,15-tetraaza-tetracyclo[15.3.1.1 12,15. $0^{5,9}$ ]docosane-6,8,1(21),17,19 -pentaene-14-carboxamide (28): White solid, m.p. 229-232 ${ }^{\circ} \mathrm{C}$, yield $80 \%,{ }^{1} \mathrm{H}-\mathrm{NMR}\left(\mathrm{CDCl}_{3}\right): \delta 9.95$ (s, 1H), $7.72(\mathrm{~s}, 1 \mathrm{H}), 7.62-7.60(\mathrm{~m}, 2 \mathrm{H}), 7.44-7.33(\mathrm{~m}, 3 \mathrm{H}), 7.17(\mathrm{~d}, 1 \mathrm{H}, J=7.4 \mathrm{~Hz}), 7.14-7.08(\mathrm{~m}, 3 \mathrm{H})$, $5.10-5.07(\mathrm{~m}, 1 \mathrm{H}), 5.04-5.01(\mathrm{~m}, 1 \mathrm{H}), 4.80(\mathrm{~d}, 1 \mathrm{H}, J=11.6 \mathrm{~Hz}), 4.72-4.66(\mathrm{~m}, 1 \mathrm{H}), 4.61-4.59(\mathrm{~m}, 1 \mathrm{H}), 4.48$ $(\mathrm{d}, 1 \mathrm{H}, J=11.6 \mathrm{~Hz}), 4.31-4.26(\mathrm{~m}, 2 \mathrm{H}), 4.04-4.01(\mathrm{~d}, 1 \mathrm{H}), 3.29-3.23(\mathrm{~m}, 2 \mathrm{H}), 2.33-2.28(\mathrm{~m}, 1 \mathrm{H})$. HRMS $\left(\mathrm{ESI}_{-} \mathrm{TOF}^{+}\right.$): $m / z$ Calcd. for $\mathrm{C}_{23} \mathrm{H}_{24} \mathrm{~N}_{5} \mathrm{O}_{4}[\mathrm{M}+\mathrm{H}]^{+}:$434.1828. Found: 434.1833.

(12R,14S)-16-Oxo-N-isobutyl-2,11-dioxa-5,6,7,15-tetraaza-tetracyclo[15.3.1.1 $\left.1^{12,15} .0^{5,9}\right]$ docosane-6,8,1(21),17,19 -pentaene-14-carboxamide (29): White solid, m.p. $200-202{ }^{\circ} \mathrm{C}$, yield $68 \%,{ }^{1} \mathrm{H}-\mathrm{NMR}\left(\mathrm{CDCl}_{3}\right): \delta 7.70$ (s, 1H), $7.67(\mathrm{~s}, 1 \mathrm{H}), 7.41(\mathrm{t}, 1 \mathrm{H}, J=7.8 \mathrm{~Hz}), 7.11(\mathrm{~d}, 1 \mathrm{H}, J=7.3 \mathrm{~Hz}), 7.07-7.06(\mathrm{~m}, 2 \mathrm{H}), 5.03-4.99$ $(\mathrm{m}, 1 \mathrm{H}), 4.92-4.90(\mathrm{~m}, 1 \mathrm{H}), 4.77(\mathrm{~d}, 1 \mathrm{H}, J=11.6 \mathrm{~Hz}), 4.68-4.66(\mathrm{~m}, 1 \mathrm{H}), 4.60-4.56(\mathrm{~m}, 1 \mathrm{H}), 4.44(\mathrm{~d}, 1 \mathrm{H}$, $J=11.6 \mathrm{~Hz}), 4.32-4.28(\mathrm{~m}, 1 \mathrm{H}), 4.23-4.22(\mathrm{~m}, 1 \mathrm{H}), 3.96-3.94(\mathrm{~m}, 1 \mathrm{H}), 3.25-3.22(\mathrm{~m}, 1 \mathrm{H}), 3.21-3.07(\mathrm{~m}, 3 \mathrm{H})$, 2.25-2.21 (m, 1H), 1.85-1.79 (m, 1H). HRMS (ESI-TOF ${ }^{+}$: $m / z$ Calcd. for $\mathrm{C}_{21} \mathrm{H}_{28} \mathrm{~N}_{5} \mathrm{O}_{4}[\mathrm{M}+\mathrm{H}]^{+}$: 414.2141. Found: 414.2147.

(4Z,8R,10S)-12-Oxo-2,7-dioxa-11-aza-tricyclo[11.3.1.1 ${ }^{8,11}$ ]octadecane-4,1(17),13,15-tetraene-10-carboxylic acid (30): White solid, m.p. $176-178{ }^{\circ} \mathrm{C}$, yield $93 \%,{ }^{1} \mathrm{H}-\mathrm{NMR}\left(\mathrm{CDCl}_{3}\right): \delta 7.15(\mathrm{t}, 1 \mathrm{H}, J=7.7 \mathrm{~Hz}), 6.67$ $(\mathrm{d}, 1 \mathrm{H}, J=7.2 \mathrm{~Hz}), 6.84(\mathrm{~s}, 1 \mathrm{H}), 6.77(\mathrm{~d}, 1 \mathrm{H}, J=7.0 \mathrm{~Hz}), 5.63-5.59(\mathrm{~m}, 2 \mathrm{H}), 4.62(\mathrm{t}, 1 \mathrm{H}, J=7.9 \mathrm{~Hz})$, $4.33-4.32(\mathrm{~m}, 2 \mathrm{H}), 4.00(\mathrm{~s}, 1 \mathrm{H}), 3.87-3.86(\mathrm{~m}, 2 \mathrm{H}), 3.55-3.54(\mathrm{~m}, 1 \mathrm{H}), 3.45-3.42(\mathrm{~m}, 1 \mathrm{H}), 2.33-2.31$ 
$(\mathrm{m}, 1 \mathrm{H}), 2.03-2.02(\mathrm{~m}, 1 \mathrm{H})$. HRMS (ESI-TOF $\left.{ }^{+}\right): \mathrm{m} / z$ Calcd. for $\mathrm{C}_{16} \mathrm{H}_{18} \mathrm{NO}_{5}[\mathrm{M}+\mathrm{H}]^{+}:$304.1185. Found: 304.1176 .

(4Z,8R,10S)-12-Oxo-2,7-dioxa-11-aza-tricyclo[11.3.1.1 ${ }^{8,11}$ Joctadecane-4,1(17),13,15-tetraene-10-carboxamide (31): Colorless oil, yield 84\%, ${ }^{1} \mathrm{H}-\mathrm{NMR}\left(\mathrm{CDCl}_{3}\right): \delta 7.31(\mathrm{~d}, 1 \mathrm{H}, J=7.3 \mathrm{~Hz}), 7.15(\mathrm{~d}, 1 \mathrm{H}, J=7.5 \mathrm{~Hz})$, $7.02(\mathrm{~s}, 1 \mathrm{H}), 6.94(\mathrm{t}, 1 \mathrm{H}, J=8.3 \mathrm{~Hz}), 5.74-5.73(\mathrm{~m}, 2 \mathrm{H}), 5.49(\mathrm{~s}, 1 \mathrm{H}), 4.93(\mathrm{t}, 1 \mathrm{H}, J=8.2 \mathrm{~Hz}), 4.63-4.55$ $(\mathrm{m}, 2 \mathrm{H}), 4.05-3.97(\mathrm{~m}, 2 \mathrm{H}), 3.92-3.89(\mathrm{~m}, 1 \mathrm{H}), 3.69(\mathrm{~s}, 1 \mathrm{H}), 2.63-2.59(\mathrm{~m}, 1 \mathrm{H}), 2.36-2.31(\mathrm{~m}, 1 \mathrm{H})$. HRMS (ESI-TOF ${ }^{+}$): $m / z$ Calcd. for $\mathrm{C}_{16} \mathrm{H}_{19} \mathrm{~N}_{2} \mathrm{O}_{4}[\mathrm{M}+\mathrm{H}]^{+}:$303.1345. Found: 303.1340 .

(4Z,8R,10S)-12-Oxo-N-phenyl-2,7-dioxa-11-aza-tricyclo[11.3.1.18,11 ]octadecane-4,1(17),13,15-tetraene-10carboxamide (32): White solid, m.p. $190-194{ }^{\circ} \mathrm{C}$, yield $77 \%,{ }^{1} \mathrm{H}-\mathrm{NMR}\left(\mathrm{CDCl}_{3}\right): \delta 9.90(\mathrm{~s}, 1 \mathrm{H}), 7.36-7.31$ $(\mathrm{m}, 3 \mathrm{H}), 7.18(\mathrm{~d}, 1 \mathrm{H}, J=7.4 \mathrm{~Hz}), 7.00-6.98(\mathrm{~m}, 1 \mathrm{H}), 6.95(\mathrm{~s}, 1 \mathrm{H}), 6.91-6.88(\mathrm{~m}, 2 \mathrm{H}), 6.73(\mathrm{t}, 1 \mathrm{H}, J=7.3 \mathrm{~Hz})$, 5.73-5.64 (m, 2H), 5.16-5.12 (m, 1H), 5.02-4.98 (m, 1H), 4.63-4.60 (m, 1H), 4.43-4.39 (m, 1H), 4.14-4.13 $(\mathrm{m}, 1 \mathrm{H}), 3.88-3.85(\mathrm{~m}, 1 \mathrm{H}), 3.75-3.73(\mathrm{~m}, 1 \mathrm{H}), 3.55(\mathrm{~d}, 1 \mathrm{H}, J=11.7 \mathrm{~Hz}), 2.72-2.68(\mathrm{~m}, 1 \mathrm{H}), 2.31-2.26$ $(\mathrm{m}, 1 \mathrm{H})$. HRMS (ESI-TOF $\left.{ }^{+}\right): \mathrm{m} / z$ Calcd. for $\mathrm{C}_{22} \mathrm{H}_{23} \mathrm{~N}_{2} \mathrm{O}_{4}[\mathrm{M}+\mathrm{H}]^{+}:$379.1658. Found: 379.1662.

(4Z,8R,10S)-12-Oxo-N-isobutyl-2,7-dioxa-11-aza-tricyclo[11.3.1.1 ${ }^{8,11}$ ]octadecane-4,1(17),13,15-tetraene-10carboxamide (33): White solid, m.p. $201-204{ }^{\circ} \mathrm{C}$, yield $71 \%,{ }^{1} \mathrm{H}-\mathrm{NMR}$ (DMSO- $\left.d_{6}\right): \delta 7.96(\mathrm{~s}, 1 \mathrm{H}), 7.33$ $(\mathrm{t}, 1 \mathrm{H}, J=7.9 \mathrm{~Hz}), 7.10(\mathrm{~d}, 1 \mathrm{H}, J=7.6 \mathrm{~Hz}), 6.99(\mathrm{~s}, 1 \mathrm{H}), 6.95(\mathrm{~d}, 1 \mathrm{H}, J=8.3 \mathrm{~Hz}), 5.70-5.66(\mathrm{~m}, 2 \mathrm{H}), 4.54$ $(\mathrm{t}, 1 \mathrm{H}, J=8.5 \mathrm{~Hz}), 4.78-4.47(\mathrm{~m}, 2 \mathrm{H}), 4.07(\mathrm{~s}, 1 \mathrm{H}), 4.01-3.94(\mathrm{~m}, 2 \mathrm{H}), 3.67-3.65(\mathrm{~m}, 1 \mathrm{H}), 3.49(\mathrm{~d}, 1 \mathrm{H}$, $J=11.8 \mathrm{~Hz}), 2,98-2.94(\mathrm{~m}, 1 \mathrm{H}), 2.87-2.85(\mathrm{~m}, 1 \mathrm{H}), 2.28-2.27(\mathrm{~m}, 1 \mathrm{H}), 1.71-1.68(\mathrm{~m}, 1 \mathrm{H}), 0.82(\mathrm{~d}, 6 \mathrm{H}$, $J=6.5 \mathrm{~Hz}$ ). HRMS (ESI-TOF ${ }^{+}$): $m / z$ Calcd. for $\mathrm{C}_{20} \mathrm{H}_{27} \mathrm{~N}_{2} \mathrm{O}_{4}[\mathrm{M}+\mathrm{H}]^{+}:$359.1971. Found: 359.1977.

(8R,10S)-12-Oxo-2,7-dioxa-11-aza-tricyclo[11.3.1.1 ${ }^{8,11}$ ]octadecane-1(17),13,15-triene-10-carboxylic acid (34): White solid, m.p. $187-190{ }^{\circ} \mathrm{C}$, yield 90\%, ${ }^{1} \mathrm{H}-\mathrm{NMR}\left(\mathrm{DMSO}-d_{6}\right): \delta 7.33(\mathrm{t}, 1 \mathrm{H}, J=7.8 \mathrm{~Hz}), 7.02(\mathrm{~d}, 1 \mathrm{H}$, $J=7.6 \mathrm{~Hz}), 6.99(\mathrm{~s}, 1 \mathrm{H}), 6.94(\mathrm{~d}, 1 \mathrm{H}, J=8.2 \mathrm{~Hz}), 4.52(\mathrm{t}, 1 \mathrm{H}, J=8.8 \mathrm{~Hz}), 4.00(\mathrm{~s}, 1 \mathrm{H}), 3.85-3.83(\mathrm{~m}, 2 \mathrm{H})$, 3.58-3.56 (m, 1H), 3.51-3.46 (m, 2H), 3.17-3.14 (m, 1H), 2.37-2.33 (m, 1H), 2.03-1.98 (m, 1H), 1.66-1.64 $(\mathrm{m}, 1 \mathrm{H}), 1.50-1.43(\mathrm{~m}, 3 \mathrm{H})$. HRMS (ESI-TOF $\left.{ }^{+}\right): \mathrm{m} / z$ Calcd. for $\mathrm{C}_{16} \mathrm{H}_{20} \mathrm{NO}_{5}[\mathrm{M}+\mathrm{H}]^{+}: 306.1341$. Found: 306.1344 .

(8R,10S)-12-Oxo-2,7-dioxa-11-aza-tricyclo[11.3.1.1 ${ }^{8,11}$ ]octadecane-1(17),13,15-triene-10-carboxamide (35): White solid, m.p. $60-63{ }^{\circ} \mathrm{C}$, yield $69 \%,{ }^{1} \mathrm{H}-\mathrm{NMR}$ (DMSO- $\left.d_{6}\right): \delta 7.48(\mathrm{~s}, 1 \mathrm{H}), 7.33(\mathrm{t}, 1 \mathrm{H}, J=7.4 \mathrm{~Hz}), 7.15$ $(\mathrm{d}, 1 \mathrm{H}, J=7.0 \mathrm{~Hz}), 7.03(\mathrm{~d}, 1 \mathrm{H}, J=6.3 \mathrm{H}), 6.94(\mathrm{~d}, 1 \mathrm{H}, J=8.1 \mathrm{~Hz}), 4.49(\mathrm{t}, 1 \mathrm{H}, J=8.5 \mathrm{~Hz}), 3.95(\mathrm{~s}, 1 \mathrm{H})$, 3.84-3.79 (m, 2H), 3.60-3.58 (m, 1H), 3.47-3.45 (m, 2H), 3.16-3.12 (m, 1H), 2.30-2.25 (m, 1H), 1.94-1.90 $(\mathrm{m}, 1 \mathrm{H}), 1.67-1.64(\mathrm{~m}, 1 \mathrm{H}), 1.48-1.43(\mathrm{~m}, 3 \mathrm{H})$. HRMS (ESI-TOF $\left.{ }^{+}\right): m / z$ Calcd. for $\mathrm{C}_{16} \mathrm{H}_{21} \mathrm{~N}_{2} \mathrm{O}_{4}[\mathrm{M}+\mathrm{H}]^{+}$: 305.1501. Found: 305.1508.

(8R,10S)-12-Oxo-N-phenyl-2,7-dioxa-11-aza-tricyclo[11.3.1.1 1,11 ]octadecane-1(17),13,15-triene-10-carboxamide (36): White solid, m.p. $119-123{ }^{\circ} \mathrm{C}$, yield 76\%, ${ }^{1} \mathrm{H}-\mathrm{NMR}\left(\mathrm{CDCl}_{3}\right): \delta 9.63(\mathrm{~s}, 1 \mathrm{H}), 7.59(\mathrm{~m}, 2 \mathrm{H}), 7.32-7.30$ $(\mathrm{m}, 3 \mathrm{H}), 7.12-7.10(\mathrm{~m}, 2 \mathrm{H}), 7.00(\mathrm{~d}, 1 \mathrm{H}, J=7.5 \mathrm{~Hz}), 6.93-6.91(\mathrm{~m}, 1 \mathrm{H}), 5.15(\mathrm{t}, 1 \mathrm{H}, J=7.7 \mathrm{~Hz}), 4.02$ (s, 1H), 3.93-3.89 (m, 2H), 3.80-3.78 (m, 1H), 3.56-3.54 (m, 1H), 3.48-3.46 (m, 1H), 3.20-3.16 (m, 1H), 2.90-2.85 (m, 1H), 2.28-2.24 (m, 1H), 1.81-1.78 (m, 1H), 1.69-1,64 (m, 4H). HRMS (ESI-TOF $\left.{ }^{+}\right): m / z$ Calcd. for $\mathrm{C}_{22} \mathrm{H}_{25} \mathrm{~N}_{2} \mathrm{O}_{4}[\mathrm{M}+\mathrm{H}]^{+}$: 381.1814. Found: 381.1811 .

(8R,10S)-12-Oxo-N-isobutyl-2,7-dioxa-11-aza-tricyclo[11.3.1.18,11]octadecane-1(17),13,15-triene-10-carboxamide (37): White solid, m.p. $207-210{ }^{\circ} \mathrm{C}$, yield 79\%, ${ }^{1} \mathrm{H}-\mathrm{NMR}\left(\mathrm{CDCl}_{3}\right): 87.36(\mathrm{t}, 1 \mathrm{H}, J=5.6 \mathrm{~Hz}), 7.30-7.29$ $(\mathrm{m}, 1 \mathrm{H}), 7.07(\mathrm{~s}, 1 \mathrm{H}), 6.97(\mathrm{~d}, 1 \mathrm{H}, J=7.4 \mathrm{~Hz}), 6.90(\mathrm{~d}, 1 \mathrm{H}, J=7.8 \mathrm{~Hz}), 4.96(\mathrm{t}, 1 \mathrm{H}, J=8.3 \mathrm{~Hz}), 3.97$ $(\mathrm{s}, 1 \mathrm{H}), 3.88-3.85(\mathrm{~m}, 2 \mathrm{H}), 3,72-3.69(\mathrm{~m}, 1 \mathrm{H}), 3.54-3.52(\mathrm{~m}, 1 \mathrm{H}), 3.44-3.43(\mathrm{~m}, 1 \mathrm{H}), 3.16-3.08(\mathrm{~m}, 3 \mathrm{H})$, 3.79-3.94 (m, 1H), 2.22-2.18 (m, 1H), 1.83-1.79 (m, 1H), 1.69-1,61 (m, 4H), $0.92(\mathrm{~d}, 6 \mathrm{H}, J=6.4 \mathrm{~Hz})$. HRMS (ESI-TOF ${ }^{+}$): $m / z$ Calcd. for $\mathrm{C}_{20} \mathrm{H}_{29} \mathrm{~N}_{2} \mathrm{O}_{4}[\mathrm{M}+\mathrm{H}]^{+}:$361.2127. Found: 361.2130 .

(9R,11S)-13-Oxo-2,8-dioxa-12-aza-tricyclo[12.3.1.19,12]nonadecane-1(18),14,16-triene-11-carboxylic acid (38): White solid, m.p. 187-190 ${ }^{\circ} \mathrm{C}$, yield 93\%, ${ }^{1} \mathrm{H}-\mathrm{NMR}\left(\mathrm{CDCl}_{3}\right): \delta 7.32(\mathrm{t}, 1 \mathrm{H}, J=7.4 \mathrm{~Hz}), 7.10(\mathrm{~s}, 1 \mathrm{H}), 7.06$ $(\mathrm{d}, 1 \mathrm{H}, J=6.5 \mathrm{~Hz}), 6.99(\mathrm{~d}, 1 \mathrm{H}, J=7.2 \mathrm{~Hz}), 4.90(\mathrm{t}, 1 \mathrm{H}, J=7.4 \mathrm{~Hz}), 4.05-3.97(\mathrm{~m}, 2 \mathrm{H}), 4.01-3.97(\mathrm{~m}, 1 \mathrm{H})$, 3.93-3.91 (m, 1H), 3.71-3.66 (m, 1H), 3.62-3.60 (m, 1H), 3.48-3.47 (m, 1H), 3.26-3.25 (m, 1H), 2.45-2.43 
$(\mathrm{m}, 2 \mathrm{H}), 1.78-1.76(\mathrm{~m}, 2 \mathrm{H}), 1.60-1.57(\mathrm{~m}, 2 \mathrm{H}), 1.48-1.45(\mathrm{~m}, 2 \mathrm{H})$. HRMS (ESI-TOF $\left.{ }^{+}\right): m / z$ Calcd. for $\mathrm{C}_{17} \mathrm{H}_{22} \mathrm{NO}_{5}[\mathrm{M}+\mathrm{H}]^{+}:$320.1498. Found: 320.1495 .

(9R,11S)-13-Oxo-2,8-dioxa-12-aza-tricyclo[12.3.1.1 ${ }^{9,12}$ ]nonadecane-1(18),14,16-triene-11-carboxamide (39): White solid, m.p. $53-55^{\circ} \mathrm{C}$, yield $68 \%,{ }^{1} \mathrm{H}-\mathrm{NMR}$ (DMSO- $\left.d_{6}\right): \delta 7.45(\mathrm{~s}, 1 \mathrm{H}), 7.36-7.32(\mathrm{~m}, 1 \mathrm{H}), 7.35$ $(\mathrm{d}, 1 \mathrm{H}, J=8.9 \mathrm{~Hz}), 7.04-7.02(\mathrm{~m}, 1 \mathrm{H}), 7.01(\mathrm{~s}, 2 \mathrm{H}), 4.42(\mathrm{t}, 1 \mathrm{H}, J=8.4 \mathrm{~Hz}), 4.02-4.01(\mathrm{~m}, 1 \mathrm{H}), 3.97-3.96$ $(\mathrm{m}, 1 \mathrm{H}), 3.92-3.91(\mathrm{~m}, 1 \mathrm{H}), 3.61-3.59(\mathrm{~m}, 1 \mathrm{H}), 3.46-3.44(\mathrm{~m}, 2 \mathrm{H}), 3.17-3.16(\mathrm{~m}, 1 \mathrm{H}), 2.38-2.36(\mathrm{~m}, 1 \mathrm{H})$, 2.01-1.95 (m, 1H), 1.45-1.44 (m, 4H), 1.38-1.34 (m, 2H). HRMS (ESI-TOF $\left.{ }^{+}\right): m / z$ Calcd. for $\mathrm{C}_{17} \mathrm{H}_{23} \mathrm{~N}_{2} \mathrm{O}_{4}$ $[\mathrm{M}+\mathrm{H}]^{+}:$319.1658. Found: 319.1651 .

(9R,11S)-13-Oxo-N-phenyl-2,8-dioxa-12-aza-tricyclo[12.3.1.19,12] nonadecane-1(18),14,16-triene-11-carboxamide (40): White solid, m.p. $88-91{ }^{\circ} \mathrm{C}$, yield $65 \%,{ }^{1} \mathrm{H}-\mathrm{NMR}\left(\mathrm{CDCl}_{3}\right): \delta 9.62(\mathrm{~s}, 1 \mathrm{H}), 7.60-7.58(\mathrm{~m}, 2 \mathrm{H})$, $7.32-7.29(\mathrm{~m}, 3 \mathrm{H}), 7.14(\mathrm{~s}, 1 \mathrm{H}), 7.10(\mathrm{~d}, 1 \mathrm{H}, J=7.2 \mathrm{~Hz}), 7.02-6.98(\mathrm{~m}, 2 \mathrm{H}), 5.11(\mathrm{t}, 1 \mathrm{H}, J=8.0 \mathrm{~Hz})$, $4.07-4.06(\mathrm{~m}, 1 \mathrm{H}), 4.03-4.00(\mathrm{~m}, 1 \mathrm{H}), 3.95-3.93(\mathrm{~m}, 1 \mathrm{H}), 3.75-3.72(\mathrm{~m}, 1 \mathrm{H}), 3.53-3.50(\mathrm{~m}, 1 \mathrm{H}), 3.45-3.43$ $(\mathrm{m}, 1 \mathrm{H}), 3.24-3.18(\mathrm{~m}, 1 \mathrm{H}), 2.87-2.82(\mathrm{~m}, 1 \mathrm{H}), 2.78-2.23(\mathrm{~m}, 1 \mathrm{H}), 1.79-1.76(\mathrm{~m}, 2 \mathrm{H}), 1.60-1.55(\mathrm{~m}, 2 \mathrm{H})$, 1.51-1.47 (m, 1H), 1.44-1.41 (m, 1H). HRMS (ESI-TOF $\left.{ }^{+}\right): m / z$ Calcd. for $\mathrm{C}_{23} \mathrm{H}_{27} \mathrm{~N}_{2} \mathrm{O}_{4}[\mathrm{M}+\mathrm{H}]^{+}$: 395.1971. Found: 395.1972.

(9R,11S)-13-Oxo-N-isobutyl-2,8-dioxa-12-aza-tricyclo[12.3.1.19,12] nonadecane-1(18),14,16-triene-11-carboxamide (41): White solid, m.p. $176-179{ }^{\circ} \mathrm{C}$, yield 71\%, ${ }^{1} \mathrm{H}-\mathrm{NMR}\left(\mathrm{CDCl}_{3}\right): \delta 7.31-7.29(\mathrm{~m}, 1 \mathrm{H}), 7.08(\mathrm{~s}, 1 \mathrm{H})$, 6.98-6.96 (m, 2H), $4.91(\mathrm{t}, 1 \mathrm{H}, J=8.0 \mathrm{~Hz}), 4.02-3.97(\mathrm{~m}, 2 \mathrm{H}), 3.93-3.89(\mathrm{~m}, 1 \mathrm{H}), 3.66-3.64(\mathrm{~m}, 1 \mathrm{H})$, 3.51-3.49 (m, 1H), 3.42-3.39 (m, 1H), 3.16-3.08 (m, 3H), 2.73-2.69 (m, 1H), 2.21-2.17 (m, 1H), 1.82-1.80 $(\mathrm{m}, 1 \mathrm{H}), 1.78-1.74(\mathrm{~m}, 2 \mathrm{H}), 1.57-1.53(\mathrm{~m}, 2 \mathrm{H}), 1.48-1.37(\mathrm{~m}, 2 \mathrm{H}), 0.92(\mathrm{~d}, 6 \mathrm{H}, J=6.7 \mathrm{~Hz})$. HRMS (ESI-TOF ${ }^{+}$): $m / z$ Calcd. for $\mathrm{C}_{21} \mathrm{H}_{31} \mathrm{~N}_{2} \mathrm{O}_{4}[\mathrm{M}+\mathrm{H}]^{+}$: 375.2284. Found: 375.2287.

(10R,12S)-14-Oxo-2,9-dioxa-13-aza-tricyclo[13.3.1.1 10,13] eicosane-1(19),15,17-triene-12-carboxylic acid (42): White solid, m.p. $201-203{ }^{\circ} \mathrm{C}$, yield 91\%, ${ }^{1} \mathrm{H}-\mathrm{NMR}$ (DMSO- $\left.d_{6}\right): \delta 7.36(\mathrm{t}, 1 \mathrm{H}, J=7.9 \mathrm{~Hz}), 7.05-7.00$ $(\mathrm{m}, 2 \mathrm{H}), 6.95(\mathrm{~s}, 1 \mathrm{H}), 4.47(\mathrm{t}, 1 \mathrm{H}, J=8.3 \mathrm{~Hz}), 4.00(\mathrm{~s}, 1 \mathrm{H}), 3.91-3.89(\mathrm{~m}, 2 \mathrm{H}), 3.60-3.47(\mathrm{~m}, 3 \mathrm{H}), 3.15-3.14$ $(\mathrm{m}, 1 \mathrm{H}), 2.36-2.32(\mathrm{~m}, 1 \mathrm{H}), 1.99-1.98(\mathrm{~m}, 1 \mathrm{H}), 1.62-1.61(\mathrm{~m}, 1 \mathrm{H}), 1.42-1.38(\mathrm{~m}, 2 \mathrm{H}), 1.30-1.15(\mathrm{~m}, 4 \mathrm{H})$. HRMS (ESI-TOF ${ }^{+}$): $m / z$ Calcd. for $\mathrm{C}_{18} \mathrm{H}_{24} \mathrm{NO}_{5}\left[\mathrm{M}+\mathrm{H}^{+}\right.$]: 334.1654. Found: 334.1658.

(10R,12S)-14-Oxo-2,9-dioxa-13-aza-tricyclo[13.3.1.110,13]eicosane-1(19),15,17-triene-12-carboxamide (43): White solid, m.p. $51-53^{\circ} \mathrm{C}$, yield $66 \%,{ }^{1} \mathrm{H}-\mathrm{NMR}$ (DMSO- $\left.d_{6}\right): \delta 7.47(\mathrm{~s}, 1 \mathrm{H}), 7.34(\mathrm{t}, 1 \mathrm{H}, J=7.5 \mathrm{~Hz}), 7.14$ $(\mathrm{d}, 1 \mathrm{H}, J=6.0 \mathrm{~Hz}), 7.03-7.00(\mathrm{~m}, 3 \mathrm{H}), 4.46(\mathrm{t}, 1 \mathrm{H}, J=8.5 \mathrm{~Hz}), 4.03-4.00(\mathrm{~m}, 2 \mathrm{H}), 3.95(\mathrm{~s}, 1 \mathrm{H}), 3.90-3.88$ $(\mathrm{m}, 2 \mathrm{H}), 3.61-3.45(\mathrm{~m}, 3 \mathrm{H}), 3.08-3.07(\mathrm{~m}, 1 \mathrm{H}), 2.27-2.23(\mathrm{~m}, 1 \mathrm{H}), 1.93-1.91(\mathrm{~m}, 1 \mathrm{H}), 1.62-1.61(\mathrm{~m}, 2 \mathrm{H})$, 1.37-1.36 (m, 2H), 1.28-1.27 (m, 2H), 1.18-1.15 (m, 2H). HRMS (ESI-TOF $\left.{ }^{+}\right): m / z$ Calcd. for $\mathrm{C}_{18} \mathrm{H}_{25} \mathrm{~N}_{2} \mathrm{O}_{4}$ $[\mathrm{M}+\mathrm{H}]^{+}:$333.1814. Found: 333.1819 .

(10R,12S)-14-Oxo-N-phenyl-2,9-dioxa-13-aza-tricyclo[13.3.1.1 10,13]eicosane-1(19),15,17-triene-12-carboxamide (44): White solid, m.p. $102-104{ }^{\circ} \mathrm{C}$, yield $69 \%,{ }^{1} \mathrm{H}-\mathrm{NMR}\left(\mathrm{CDCl}_{3}\right): \delta 9.66(\mathrm{~s}, 1 \mathrm{H}), 7.59-7.57(\mathrm{~m}, 2 \mathrm{H})$, 7.33-7.28 (m, 3H), $7.11(\mathrm{~s}, 1 \mathrm{H}), 7.08(\mathrm{t}, 1 \mathrm{H}, J=7.4 \mathrm{~Hz}), 7.01-6.97(\mathrm{~m}, 2 \mathrm{H}), 5.12(\mathrm{t}, 1 \mathrm{H}, J=8.1 \mathrm{~Hz}), 4.02$ $(\mathrm{s}, 1 \mathrm{H}), 3.99-3.94(\mathrm{~m}, 2 \mathrm{H}), 3.76-3.74(\mathrm{~m}, 1 \mathrm{H}), 3.47-3.44(\mathrm{~m}, 2 \mathrm{H}), 3.17-3.13(\mathrm{~m}, 1 \mathrm{H}), 2.88-2.83(\mathrm{~m}, 1 \mathrm{H})$, 2.27-2.22 (m, 1H), 1.79-1.77 (m, 2H), 1.52-1.51 (m, 2H), 1.42-1.37 (m, 2H), 1.29-1.26 (m, 2H). HRMS (ESI-TOF ${ }^{+}$): $m / z$ Calcd. for $\mathrm{C}_{24} \mathrm{H}_{29} \mathrm{~N}_{2} \mathrm{O}_{4}\left[\mathrm{M}+\mathrm{H}^{+}\right]$: 409.2127. Found: 409.2130 .

(10R,12S)-14-oxo-N-Isobutyl-2,9-dioxa-13-aza-tricyclo[13.3.1.110,13]eicosane-1(19),15,17-triene-12-carboxamide (45): White solid, m.p. $83-85{ }^{\circ} \mathrm{C}$, yield $74 \%,{ }^{1} \mathrm{H}-\mathrm{NMR}\left(\mathrm{CDCl}_{3}\right): \delta 7.34(\mathrm{t}, 1 \mathrm{H}, J=5.5 \mathrm{~Hz}), 7.32-7.28$ $(\mathrm{m}, 1 \mathrm{H}), 7.07(\mathrm{~s}, 1 \mathrm{H}), 6.97-6.95(\mathrm{~m}, 2 \mathrm{H}), 4.93(\mathrm{t}, 1 \mathrm{H}, J=8.1 \mathrm{~Hz}), 3.97-3.90(\mathrm{~m}, 3 \mathrm{H}), 3.67(\mathrm{~m}, 1 \mathrm{H}), 3.43-3.41$ $(\mathrm{m}, 2 \mathrm{H}), 3.17-3.06(\mathrm{~m}, 3 \mathrm{H}), 2.76-2.71(\mathrm{~m}, 1 \mathrm{H}), 2.20-2.16(\mathrm{~m}, 1 \mathrm{H}), 1.83-1.79(\mathrm{~m}, 1 \mathrm{H}), 1.50-1.48(\mathrm{~m}, 2 \mathrm{H})$, 1.40-1.38 (m, 4H), 1.26-1.23 (m, 2H), $0.92(\mathrm{~d}, 6 \mathrm{H}, J=6.4 \mathrm{~Hz})$. HRMS (ESI-TOF $\left.{ }^{+}\right): m / z$ Calcd. for $\mathrm{C}_{22} \mathrm{H}_{33} \mathrm{~N}_{2} \mathrm{O}_{4}[\mathrm{M}+\mathrm{H}]^{+}$: 389.2440. Found: 389.2439. 


\subsection{Cytotoxicity Assays}

The human lung cancer cell line A549, breast cancer cell line MDA-MB-231 and hepatocarcinoma cell line Hep G2 were cultured in Dulbecco's modified Eagle's medium (DMEM) supplemented with antibiotics (penicillin $50 \mathrm{U} / \mathrm{mL}$; streptomycin $50 \mu \mathrm{g} / \mathrm{mL}$ ) and $10 \%$ FCS. The incubation was at $37^{\circ} \mathrm{C}$ in a humidified atmosphere of $5 \% \mathrm{CO}_{2}$ in air before experiments. Cells were first seeded at a density of 8000 cells/well in a 96-well plate for 48 hours. Solutions containing respective concentrations of compounds were added into wells and incubation continued for another 24 hours. After that, the MTT (3-(4,5-dimethylthiazol-2-yl)-2,5-diphenyltetrazolium bromide) dye stock solution $(10 \mu \mathrm{L}, 5 \mathrm{mg} / \mathrm{mL})$ was added to each well. After $4 \mathrm{~h}$, the supernatant was removed and DMSO $(100 \mu \mathrm{L})$ was added to solubilize the MTT. The absorbance was measured at a wave length of $490 \mathrm{~nm}\left(\mathrm{~A}_{490 \mathrm{~nm}}\right)$ on an ELISA microplate reader. Results were expressed as $\mathrm{IC}_{50}$ values.

\section{Conclusions}

In summary, we have established the cyclization of 13- to 15-member macrocycles which contain alkyl-alkyl ether and alkyl-aryl ether linkers based on incorporation of 1,3-(meta)-benzene rings into hydroxyproline under azide-alkyne cycloaddition and amide formation conditions. The macrocyclization strategy will be further used to expand the scope and diversity of these macrocyclic derivatives. The initial biological results provided preliminary basis for further structural optimization of hydroxyproline-based macrocycles as promising inhibitors against lung cancer cell line A549, breast cancer cell line MDA-MB-231 and hepatocarcinoma cell line Hep G2. Efforts to optimize the structure of compound 33 to further improve its potency are ongoing.

Supplementary Materials: Supplementary materials are available online at www.mdpi.com/1420-3049/ 21/2/212/s1.

Acknowledgments: Financial support from the Natural Science Foundation of Shandong Province (No. ZR2014BL028) and the opening research funding of State Key Laboratory of Bioactive Substance and Function of Natural Medicines, Institute of Materia Medica, Chinese Academy of Medical Sciences and Peking Union Medical College is gratefully acknowledged.

Author Contributions: D.T., G.C., and L.H. designed the research; G.C., K.Y. and Y.L. performed the synthetic work, L.H. was responsible for the direction of the biological research. D.T. was also responsible for the correspondence of the manuscript, whereas G.C. and L.H. mainly wrote the manuscript. All authors read and approved the final manuscript.

Conflicts of Interest: The authors declare no conflict of interest.

\section{References}

1. Giordanetto, F.; Kihlberg, J. Macrocyclic drugs and clinical candidates: What can medicinal chemists learn from their properties. J. Med. Chem. 2014, 57, 278-295. [CrossRef] [PubMed]

2. Wessjohann, L.A.; Ruijter, E.; Daniel, G.R.; Brandt, W. What can a chemist learn from nature's macrocycles?-A brief, conceptual view. Mol. Dive. 2005, 9, 171-186. [CrossRef]

3. Driggers, E.M.; Hale, S.P.; Lee, J.; Terrett, N.K. The exploration of macrocycles for drug discovery-An underexploited structural class. Nat. Rev. Drug Discov. 2008, 7, 608-624. [CrossRef] [PubMed]

4. Mallinson, J.; Collins, I. Macrocycles in new drug discovery. Future Med. Chem. 2012, 4, 1409-1438. [CrossRef] [PubMed]

5. Bogden, A.R.; Davies, N.L.; James, K. Comparison of diffusion coefficients for matched pairs of macrocyclic and linear molecules over a drug-like molecular weight range. Org. Biomol. Chem. 2011, 9, 7727-7733. [CrossRef] [PubMed]

6. Marsanlt, E.; Peterson, M.I. Macrocycles are great cycles: Applications, opportunities, and challenges of synthetic macrocycles in drug discovery. J. Med. Chem. 2011, 54, 1961-2004. [CrossRef] [PubMed]

7. Kohll, R.M.; Walsh, C.T.; Burkart, M.D. Biomimetic synthesis and optimization of cyclic peptide antibiotics. Nature 2002, 418, 658-661. [CrossRef] [PubMed]

8. Nagarajan, R. Structure-activity relationships of vancomycin-type glycopeptides antibiotics. J. Antibiot. 1993, 46, 1181-1195. [CrossRef] [PubMed] 
9. Gerhard, U.; Mackay, R.A.; Williams, D.H. The role of the sugar and chlorine substituents in the dimerization of vancomycin antibiotics. J. Am. Chem. Soc. 1993, 115, 232-237. [CrossRef]

10. Walsh, C.T. Vancomycin resistance: Decoding the molecular logic. Science 1993, 261, 308-309. [CrossRef] [PubMed]

11. Wright, G.D.; Walsh, C.T. D-Alanyl-D-alanine ligases and the molecular mechanism of vancomycin resistance. Acc. Chem. Res. 1992, 25, 468-473. [CrossRef]

12. Yasuzawa, T.; Shirahata, K.; Sano, H. K-13, a novel inhibitir of angiotensin I converting enzyme produced by micromonospora halophytica subsp. exilisia. II. Structure determination. J. Antibiot. 1987, 40, 455-458. [CrossRef] [PubMed]

13. Bigot, A.; Bois-Choussy, M.; Zhu, J. An efficient total synthesis of K-13, a non-competitive inhibitor of ACE I. Tetrahedron Lett. 2000, 41, 4573-4578. [CrossRef]

14. Tamai, S.; Kaneda, M.; Nakamura, S. Piperazinomycin, a new antifungal antibiotic I. Fermentation, isolation, characterization and biological properties. J. Antibiot. 1982, 35, 1130-1136. [CrossRef] [PubMed]

15. Morita, H.; Yamamiya, T.; Takeya, K.; Itokawa, H. New antitumor bicyclic hexapeptides, RA-XI, -XII and -XIV from Rubia cordifolia. Chem. Pharm. Bull. 1992, 40, 1352-1354. [CrossRef] [PubMed]

16. Itokawa, H.; Takeya, K. Antitumor Substtances from Higher Plants. Heterocycles 1993, 35, 1467-1501. [CrossRef]

17. Pyluck, A.; Yuan, R.; Galligan, E., Jr.; Primakoff, P.; Myles, D.; Sampson, N.S. ECD peptides inhibit in vitro fertilization in mice. Bioorg. Med. Chem. Lett. 1997, 7, 1053-1058. [CrossRef]

18. Feng, Y.; Wang, Z.; Jin, S.; Burgess, K. SNAr cyclizations to from cyclic peptidomimetics of-turus. J. Am. Chem. Soc. 1998, 120, 10768-10769. [CrossRef]

19. Virgilio, A.; Bray, A.A.; Zhang, W.; Trinh, L.; Snyder, M.; Morrissey, M.M. Synthesis and evaluation of a library of peptidomimetics based upon the $\beta$-turn. Tetrahedron 1997, 53, 6635-6644. [CrossRef]

20. Burgess, K.; Lim, D.; Bois-Choussy, M.; Zhu, J. Rapid and efficient solid phase syntheses of cyclic peptides with endocyclic biaryl ether bonds. Tetrahedron Lett. 1997, 38, 3345-3348. [CrossRef]

21. Tschcsche, R.; Kaufßmann, E.U.; Eckhardt, G. Alkaloide aus rhamnaceen, XVI. Über die struktur des zizyphins-a. Tetrohedron Lett. 1973, 28, 2577-2580. [CrossRef]

22. Schmidt, U.; Lieberknecht, A.; Bökens, H.; Griesser, H. Total synthesis of zizyphin A and N-acetylzizyphin B. Angew. Chem. Int. Ed. Engl. 1981, 20, 1026-1027. [CrossRef]

23. Lin, H.-Y.; Chen, C.H.; You, B.J.; Lin, K.C.S.C.; Le, S.-S. Cyclopeptide Alkaloids from Paliurus ramossisimus. J. Nat. Prod. 2000, 63, 1338-1343. [CrossRef] [PubMed]

24. Toumi, M.; Couty, F.; Evano, G. Total synthesis of the cyclopeptide alkaloid paliurine E. Insights into Macrocyclization by Ene-Enamide RCM. J. Org. Chem. 2008, 73, 1270-1281. [CrossRef] [PubMed]

25. Lexi-Comp Online. Medical Database; Lexi-Comp, Inc.: Hudson, OH, USA, 2013.

26. Chen, S.C.A.; Slavin, M.A.; Sorrell, T.C. Echinocandin antifungal drugs in fungal infections: A Comparison. Drugs 2011, 71, 11-41. [CrossRef] [PubMed]

27. Holt, S.L.; Drew, R.H. Echinocandins: Addressing outstanding questions surrounding treatment of invasive fungal infections. Am. J. Health Syst. Pharm. 2011, 68, 1207-1220. [CrossRef] [PubMed]

28. Wiederhold, N.P.; Lewis, R.E. The echinocandin antifungals: An overview of the pharmacology, spectrum and clinical efficacy. Expert Opin. Investig. Drugs 2003, 12, 1313-1333. [CrossRef] [PubMed]

29. McCauley, J.A.; McIntyre, C.J.; Rudd, M.T.; Nguyen, K.T.; Romano, J.J.; Butcher, J.W.; Gilbert, K.F.; Bush, K.J.; Holloway, M.K.; Swestock, J.; et al. Discovery of vaniprevir (MK-7009), a macrocyclic hepatitis C virus NS3/4a protease inhibitor. J. Med. Chem. 2010, 53, 2443-2463. [CrossRef] [PubMed]

30. Song, Z.J.; Tellers, D.M.; Journet, M.; Kuethe, J.T.; Lieberman, D.; Humphrey, G.; Zhang, F.; Peng, Z.; Waters, M.S.; Zewge, D.; et al. Synthesis of vaniprevir (MK-7009): Lactamization to Prepare a 22-Membered Macrocycle. J. Org. Chem. 2011, 76, 7804-7815. [CrossRef] [PubMed]

31. Seiwert, S.D.; Andrews, S.W.; Jiang, Y.; Serebryany, V.; Tan, H.; Kossen, K.; Rajagopalan, P.T.; Misialek, S.; Stevens, S.K.; Stoycheva, A.; et al. Preclinical Characteristics of the Hepatitis C Virus NS3/4A Protease Inhibitor ITMN-191 (R7227). Antimicrob. Agents Chemother. 2008, 52, 4432-4441. [CrossRef] [PubMed]

32. Hinrichsen, H.; Benhamou, Y.; Wedemeyer, H.; Reiser, M.; Sentjens, R.E.; Calleja, J.L.; Forns, X.; Erhardt, A.; Cronlein, J.; Chaves, R.L.; et al. Short-term antiviral efficacy of BILN 2061, a hepatitis C virus serine protease inhibitor, in hepatitis C genotype 1 patients. Gastroenterology 2004, 127, 1347-1355. [CrossRef] [PubMed] 
33. Hong, H.; Huang, L.J.; Teng, D.W. A spirocyclic oxindole analogue: Synthesis and Antitumor Activities. Chin. Chem. Lett. 2011, 9, 1009-1012. [CrossRef]

34. Huang, L.J.; Teng, D.W. An improved and scalable process for 3,8-diazabicyclo[3.2.1]octane analogues. Chin. Chem. Lett. 2011, 5, 523-526. [CrossRef]

35. Cao, G.; Long, F.; Zhao, Y.; Wang, Y.; Huang, L.; Teng, D. Synthesis of spiropyrrolidinyl-benzoisothiazoline derivatives by 1,3-dipolar cycloaddition of benzoisothiazole-2,2-dioxide-3-ylidenes and azomethine ylide. Tetrahedron 2014, 70, 9359-9365. [CrossRef]

36. Huisgen, R. 1,3-Dipor Cycloadditions. Past and Future. Angew. Chem. Int. Ed. 1963, 2, 565-598. [CrossRef]

37. Rostovtsev, V.V.; Green, L.G.; Fokin, V.V.; Sharpless, K.B. A Stepwise Huisgen Cycloaddition Process: Copper(I)-Catalyzed Regioselective "Ligation" of Azides and Terminal Alkynes. Angew. Chem. Int. Ed. 2002, 41, 2596-2599. [CrossRef]

38. Tornøe, C.W.; Christensen, C.; Meldal, M. Peptidotriazoles on Solid Phase: [1,2,3]-Triazoles by Regiospecific Copper(I)-Catalyzed 1,3-Dipolar Cycloadditions of Terminal Alkynes to Azides. J. Org. Chem. 2002, 67, 3057-3064. [CrossRef] [PubMed]

39. Wang, Q.; Chan, T.R.; Hilgraf, R.; Fokin, V.V.; Sharpless, K.B.; Finn, M.G. Bioconjugation by Copper(I)-Catalyzed Azide-Alkyne [3+2] Cycloaddition. J. Am. Chem. Soc. 2003, 125, 3192-3193. [CrossRef] [PubMed]

40. Wu, P.; Feldman, A.K.; Nugent, A.K.; Hawker, C.J.; Scheel, A.; Voit, B.; Pyun, J.; Fréchet, J.M.J.; Sharpless, K.B.; Fokin, V.V. Efficiency and Fidelity in a Click-Chemistry Route to Triazole Dendrimers by the Copper(I)-Catalyzed Ligation of Azides and Alkynes. Angew. Chem. Int. Ed. 2004, 43, 3928-3932. [CrossRef] [PubMed]

41. Yoo, E.J.; Ahlquist, M.; Kim, S.H.; Bae, I.; Fokin, V.V.; Sharpless, K.B.; Chang, S. Copper-Catalyzed Synthesis of N-Sulfonyl-1,2,3-triazoles: Controlling Selectivity. Angew. Chem. Int. Ed. 2007, 46, 1730-1733. [CrossRef] [PubMed]

42. Kumar, D.; Reddy, V.B.; Varma, R.S. A facile and regioselective synthesis of 1,4-disubstituted 1,2,3-triazoles using click chemistry. Tetrahedron Lett. 2009, 50, 2065-2068. [CrossRef]

43. Zhang, L.; Chen, X.; Xue, P.; Sun, H.H.U.; Williams, I.D.; Sharpless, K.B.; Fokin, V.V.; Jia, G.J. Ruthenium-Catalyzed Cycloaddition of Alkynes and Organic Azides. J. Am. Chem. Soc. 2005, 127, 15998-15999. [CrossRef] [PubMed]

44. Boren, B.C.; Narayan, S.; Rasmussen, L.K.; Zhang, L.; Zhao, H.; Lin, Z.; Jia, G.; Fokin, V.V. Ruthenium-Catalyzed Azide-Alkyne Cycloaddition: Scope and Mechanism. J. Am. Chem. Soc. 2008, 130, 8923-8930. [CrossRef] [PubMed]

45. Rasmussen, L.K.; Boren, B.C.; Fokin, V.V. Ruthenium-Catalyzed Cycloaddition of Aryl Azides and Alkynes. Org. Lett. 2007, 9, 5337-5339. [CrossRef] [PubMed]

46. Wu, P.; Fokin, V.V. Catalytic azide-alkyne cycloaddition: Reactivity and applications. Aldrichim. Acta 2007, 40, 7-17. [CrossRef]

47. Kelly, A.R.; Wei, J.; Kesavan, S.; Marié, J.-C.; Windmon, N.; Young, D.W.; Marcaurelle, L.A. Accessing Skeletal Diversity Using Catalyst Control: Formation of $n$ and $n+1$ Macrocyclic Triazole Rings. Org. Lett. 2009, 11, 2257-2260. [CrossRef] [PubMed]

48. Grubbs, R.H. Handbook of Metathesis; Wiley-VCH: Weinheim, Germany, 2003.

49. Fürstner, A.; Langemann, K. Conformationally Unbiased Macrocyclization Reactions by Ring Closing Metathesis. J. Org. Chem. 1996, 61, 3942-3943. [CrossRef] [PubMed]

50. Kulkarni, A.K.; Diver, S.T. Ring Synthesis by Stereoselective, Methylene-Free Enyne Cross Metathesis. J. Am. Chem. Soc. 2004, 126, 8110-8111. [CrossRef] [PubMed]

51. Fürstner, A.; Davies, P.W. Alkyl methathesis. Chem. Commun. 2005, 18, 2307-2320. [CrossRef] [PubMed]

52. Gradillas, A.; Pérez-Castells, J. Macrocyclization by Ring-Closing Metathesis in the Total Synthesis of Natural Products: Reaction Conditions and Limitations. Angew. Chem. Int. Ed. 2006, 45, 6086-6101. [CrossRef] [PubMed]

53. Illuminati, G.; Mandolini, L. Ring closure reactions of bifunctional chain molecules. Acc. Chem. Res. 1981, 14, 95-102. [CrossRef] 
54. Galli, L.C.; Mandolini, L. The Role of Ring Strain on the Ease of Ring Closure of Bifunctional Chain Molecules. Eur. J. Org. Chem. 2000, 18, 3117-3125. [CrossRef]

55. Conrad, J.C.; Eelman, M.D.; Silva, J.A.D.; Monfette, S.; Parnas, H.H.; Snelgrove, J.L.; Fogg, D.E. Oligomers As Intermediates In Ring-Closing Metathesis. J. Am. Chem. Soc. 2007, 129, 1024-1025. [CrossRef] [PubMed]

Sample Availability: Samples of the compounds 16-39 are available from the authors.

(C) 2016 by the authors; licensee MDPI, Basel, Switzerland. This article is an open access article distributed under the terms and conditions of the Creative Commons by Attribution (CC-BY) license (http:/ / creativecommons.org/licenses/by/4.0/). 